\title{
Hydrothermal ageing of tetragonal zirconia porous membranes Effect of thermal residual stresses on the phase stability
}

DOI:

10.1016/j.corsci.2018.06.042

\section{Document Version}

Accepted author manuscript

Link to publication record in Manchester Research Explorer

Citation for published version (APA):

Guo, F., Liu, Y., Wang, G., Yi, M., Cai, H., Wang, X., Xiao, P., \& Zhao, X. (2018). Hydrothermal ageing of tetragonal zirconia porous membranes Effect of thermal residual stresses on the phase stability. Corrosion Science. https://doi.org/10.1016/j.corsci.2018.06.042

\section{Published in:}

Corrosion Science

\section{Citing this paper}

Please note that where the full-text provided on Manchester Research Explorer is the Author Accepted Manuscript or Proof version this may differ from the final Published version. If citing, it is advised that you check and use the publisher's definitive version.

\section{General rights}

Copyright and moral rights for the publications made accessible in the Research Explorer are retained by the authors and/or other copyright owners and it is a condition of accessing publications that users recognise and abide by the legal requirements associated with these rights.

\section{Takedown policy}

If you believe that this document breaches copyright please refer to the University of Manchester's Takedown Procedures [http://man.ac.uk/04Y6Bo] or contact uml.scholarlycommunications@manchester.ac.uk providing relevant details, so we can investigate your claim.

\section{OPEN ACCESS}




\section{Manuscript Details}

\section{Manuscript number}

Title

\section{Article type}

CORSCI_2018_127_R2

Hydrothermal ageing of tetragonal zirconia porous membranes: Effect of thermal residual stresses on the phase stability

Full Length Article

\section{Abstract}

Yttria-stabilized tetragonal zirconia hollow fiber membranes were aged in aqueous solution for investigating effect of porosity and residual stress on hydrothermal ageing. The monoclinic phase was evaluated by XRD and confocal micro-Raman spectra, to be $\leq 5.0 \mathrm{vol} \%$ and $\leq 60 \mathrm{vol} \%$ even after $100 \mathrm{~h}$ ageing, respectively. It is the first time to clarify the hydrothermal ageing mechanism of highly porous zirconia membranes. Highest monoclinic phase amount occurred at the interface transition regions of the aged samples, which suggested that the thermal residual stress can noticeably promote the monoclinic phase growth rate of the grain boundaries.

\section{Keywords}

Taxonomy

Corresponding Author

Corresponding Author's Institution

Order of Authors hydrothermal ageing; zirconia; phase transformation; porous membranes; thermal residual stresses

Phase Transformation, Residual Stress, Sintering, Zirconia, Porous Material, Hydrothermal Corrosion

Fangwei Guo

Shanghai Jiaotong University

Fangwei Guo, Yang Liu, Guowei Wang, Meiyu Yi, Hangyue Cai, Xin Wang, Ping Xiao, xiaofeng zhao 


\section{Highlights}

- It is the first time to clarify the hydrothermal ageing mechanism of highly porous zirconia membranes.

- Monoclinic phase grains dispersed in the whole membranes.

- Highest monoclinic phase amount occurred at the interface transition regions.

- Asymmetric microstructure and porosity gradient led to residual stress after sintering.

- The thermal residual stress triggers the monoclinic phase growth. 


\section{Hydrothermal ageing of tetragonal zirconia porous membranes:}

\section{Effect of thermal residual stresses on the phase stability}

Fangwei Guo ${ }^{*}$, Yang Liu $^{b}$, Guowei Wang ${ }^{c}$, Meiyu Yi ${ }^{a}$, Huangyue Cai ${ }^{a}$, Xin Wang ${ }^{d}$, Ping Xiao ${ }^{e}$, Xiaofeng Zhao

a School of Materials Science and Engineering, Shanghai Jiao Tong University, Shanghai 200240, China

b Forschungszentrum Juelich GmbH, Juelich 52425, Germany

c China Nuclear Power Engineering \&Technology Co. Ltd., Shanghai 200240, China

d Konca Solar Cell Co. Ltd., Wuxi 214174, China

e School of Materials, University of Manchester, MSS Tower, Manchester M13 9PL, United Kingdom

\section{Graphical abstract}

(a)

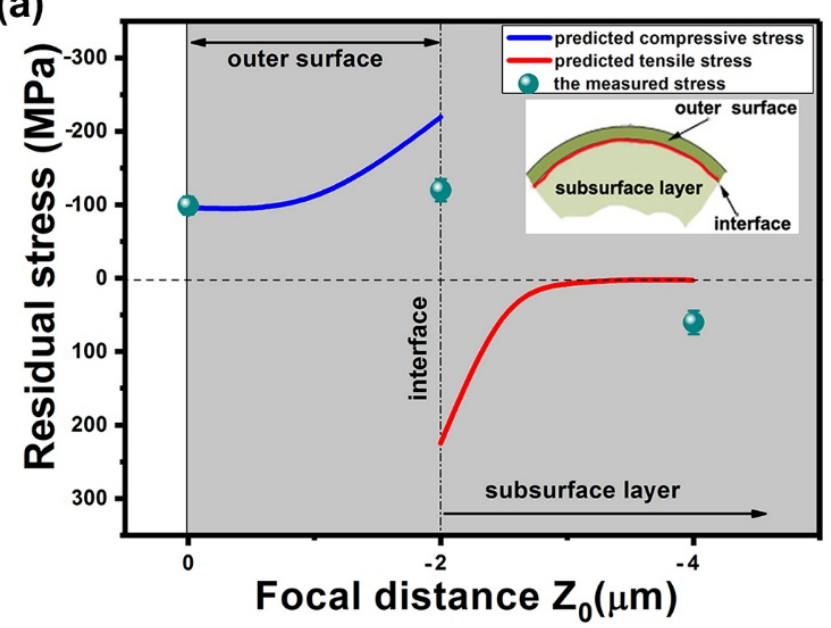

(b) outer surface

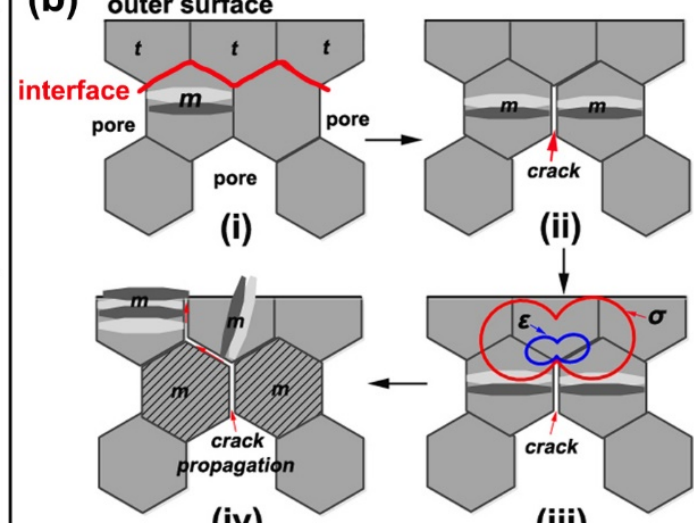

(iv) (iii) 


\begin{abstract}
Yttria-stabilized tetragonal zirconia hollow fiber membranes were aged in aqueous solution for investigating effect of porosity and residual stress on hydrothermal ageing. The monoclinic phase was evaluated by XRD and confocal micro-Raman spectra, to be $\leq 5.0 \mathrm{vol} \%$ and $\leq 60 \mathrm{vol} \%$ even after $100 \mathrm{~h}$ ageing, respectively. It is the first time to clarify the hydrothermal ageing mechanism of highly porous zirconia membranes. Highest monoclinic phase amount occurred at the interface transition regions of the aged samples, which suggested that the thermal residual stress can noticeably promote the monoclinic phase growth rate of the grain boundaries.
\end{abstract}

Keywords: hydrothermal ageing; zirconia; phase transformation; porous membranes; thermal residual stresses

\title{
1. Introduction
}

Aqueous micro/nano-filtration modules composed of hollow fiber membranes (HFM) have highest packing density, and that made of yttria stabilized tetragonal zirconia polycrystals (Y-TZP) possess improved fracture toughness as well [1-3]. However, the phase transformation from tetragonal to monoclinic $(t-m)$ zirconia can occur in the presence of water, even at room temperature (namely low temperature degradation or hydrothermal ageing) [4, 5]. The hydrothermal ageing would destabilize the Y-TZP ceramics and generally wreck the modules. The hydrothermal ageing performances of dense Y-TZP ceramics applied for dental and orthopaedic implants have been extensively documented in literature [6-11]. To date, the hydrothermal ageing mechanism is still in debate. Irrespective of the hydrothermal ageing, the nucleation of phase transformation in Y-TZP is believed to be stress assisted and usually takes place at grain boundaries at the exposed surface of samples and then proceeds inward $[6,9,12]$. Very often the presence of surface uplift due to $m$ phase grains/nuclei is taken as an indicator of the ceramic degradation and microcracking. The highest amount of $m$ phase was found at the exposed surface of the aged samples. The destabilized Y-TZP samples consequently show increased wear 
rate, intergranular microcracking, and reduction of mechanical strength $[10,11]$. However, in some cases [4, 13-16], no $m$ phase feature was observed at the aged samples' surfaces which were subjected to the applied or residual tensile stresses (50 $\sim 200 \mathrm{MPa}$ ). The abnormal ageing performances raise a conjecture that the maximum ageing rate or the maximum transformation can occur at different locations due to the microstructure/stress distributions in the specific samples. If the phase transformation initially happens at grain boundaries of the subsurface layer and/or the transformation rate subsurface layer is faster than the free surface layer, the service lifetime of the aged samples evaluated by the current theory would be overestimated for years [8]. In comparison to the Y-TZP bulks, the porous membranes have a higher possibility of the subsurface layer ageing, because water molecules could infiltrate and wet the whole samples.

It is known that shear and tensile stresses destabilize the grains, whereas compressive stresses stabilize the grains. Cold manufacturing processes give the products' surface residual stresses that are mainly shear stresses, affecting the nucleation rate of the hydrothermal ageing $[6,16-18]$. The internal stress situation in Y-TZP grains of stress free samples influenced their own phase stability, which was illustrated by the in-situ TEM observations of the aged grains $[6-8,10]$. Our recent work [19] revealed that residual stresses of $\sim 200 \mathrm{MPa}$ existed in the 3Y-TZP HFM sintered at $1300{ }^{\circ} \mathrm{C}$ for $4 \mathrm{~h}$. The residual stresses were results of thermal histories of the 3Y-TZP membrane with asymmetric microstructure and highly porosity gradient, which probably affect the hydrothermal ageing. Therefore, the 3Y-TZP hollow fiber membranes prepared by using the spinning-sintering method was used as the model samples. The objectives of this study are to find out where the early $t-m$ phase transformation happens for the samples and the influencing factors. The samples were aged in 10 wt. $\% \mathrm{NaOH}$ solution at $100{ }^{\circ} \mathrm{C}$, where $t-m$ phase transformation of the surface and the subsurface layer as a function of ageing time was investigated, as quantified by X-ray diffraction and confocal micro-Raman spectroscopy. 


\section{Materials and methods}

\subsection{Materials}

Yttria-stabilized tetragonal zirconia powder $\left(3 \mathrm{~mol} \% \mathrm{Y}_{2} \mathrm{O}_{3}\right.$, purity of $99.9 \%, 90 \pm$ $25 \mathrm{~nm}$, JiangxiFanmeiya Materials Co., Ltd.) was studied. The Fe (acac) $)_{3}$ powder (Iron acetylacetonate, purity of $99.9 \%, 50 \pm 10 \mathrm{~nm}$, Sigma-Aldrich, China) was used as the "sintering aid" in order to avoid interference of fast grain growth and severe yttria segregation induced by high sintering temperature $\left(>1300{ }^{\circ} \mathrm{C}\right)$. The $\mathrm{Fe}(\mathrm{acac})_{3}$ was added into the $3 \mathrm{~mol} \%$ yttria-stabilized tetragonal zirconia (3Y-TZP) powder by a molar ratio of $0.5 \%$. The powder mixture was milled by using $400 \mathrm{rpm}$ speed for 24 h. In the attrition mill procedure, the $\mathrm{Fe}^{3+}$ ions fully dissolved into $3 \mathrm{Y}-\mathrm{TZP}$ and formed the Fe doped 3Y-TZP solid solution powder. The powder was used to spin green hollow fiber membranes. Polyethersulfone (PES, BD-5, Beishide Chemical Reagent Factory), N-methyl-2-pyrrolidone (NMP, AR Grade, purity of 99\%, GuanghuaSci-Tech Co., Ltd.) and polyvinylpyrrolidone (PVP, K30, Sinopharm Chemical Reagent Co., Ltd.) were used as the polymer binder, the solvent and additive respectively to prepare the spinning solution. Deionized water was used as the internal and external coagulants, respectively. Sodium hydroxide powder $(\mathrm{NaOH}$, AR, Guangzhou Chemical Reagent Factory) was used in the ageing tests.

\subsection{Preparation of 3Y-TZP hollow fiber membranes}

3Y-TZP, PES and NMP (the mass ratio of 5:1:4) were mixed to form homogenous polymer slurry. The well mixed suspension was transferred into a stainless steel reservoir of a home-made spinning device. The green precursors of 3Y-TZP hollow fiber membranes (3Y-TZP HFM) were prepared by using a spinning-sintering method, the detailed procedure were reported everywhere [1-3]. The green precursors were sintered in a muffle furnace at $1100{ }^{\circ} \mathrm{C}, 1150{ }^{\circ} \mathrm{C}, 1200{ }^{\circ} \mathrm{C}$ and $1250{ }^{\circ} \mathrm{C}$ for $4 \mathrm{~h}$ with the heating/cooling rate of $5{ }^{\circ} \mathrm{C} / \mathrm{min}$. Our preliminary experiments showed that the outer surface of the 3 Y-TZP HFM sintered above $1250^{\circ} \mathrm{C}$ became a dense layer that lost permeability. The sintered samples are denoted accordingly as '1100-HFM', 
'1150-HFM', '1200-HFM' and '1250-HFM' for short, respectively. The tetragonal to cubic dual- phase separation $(t-c)$ could be expected to occur in all Y-TZP ceramics sintered or deposited with a composition falling in the two-phase layers of the zirconia-yttria phase diagram [6], which is often considered as the second critical factor influencing the hydrothermal ageing of Y-TZP ceramics due to the severe yttrium segregation at grain boundaries. Therefore, the 3Y-TZP HFM greens were also sintered at $1300{ }^{\circ} \mathrm{C}$ and $1500{ }^{\circ} \mathrm{C}$ for investigating the temperature dependence of the cubic phase amount. The samples investigated were $100 \mathrm{~mm}$ in length, $1.2 \mathrm{~mm}$ in the outer diameter and $0.7 \mathrm{~mm}$ in the inner diameter.

\subsection{Accelerated hydrothermal ageing test}

The ageing rate of the $3 \mathrm{Y}-\mathrm{TZP}$ ceramics is temperature dependent. The vapor $134^{\circ} \mathrm{C}, 2$ bar pressure is very often used for the study of ageing of dense $3 \mathrm{Y}-\mathrm{TZP}$ bulks [6-8]. In this study, the applied stress originated from the 2 bar pressure could affect the hydrothermal ageing behavior of the porous membrane samples with residual stresses derived from sintering procedures. Additionally, the ceramic micro/nano filtration membranes generally work at the temperature range of $5 \sim 100$ ${ }^{\circ} \mathrm{C}[20,21]$. Therefore, hydrothermal treatment at $100 \pm 0.6{ }^{\circ} \mathrm{C}$ (the boiling water temperature) was chosen to accelerate the ageing rate of the 3Y-TZP HFM. The ageing rate of the dense $3 \mathrm{Y}$-TZP samples was quite slow at $100 \pm 0.6{ }^{\circ} \mathrm{C}$ water, which is time-consuming $(\sim 1666 \mathrm{~h}$ estimated according to the ref [11]). Thus, the $10 \mathrm{wt} . \%$ $\mathrm{NaOH}$ aqueous solution was selected to be the ageing medium in order to shorten the ageing experiment period. The as-sintered membranes were immersed in $10 \mathrm{wt} . \%$ $\mathrm{NaOH}$ aqueous solution in a flask equipped with a reflux condenser. The flask was heated to $100 \pm 0.6{ }^{\circ} \mathrm{C}$ with an oil bath and the solution was under continuous magnetic stirring for $8 \mathrm{~h}, 22 \mathrm{~h}, 50 \mathrm{~h}$ and $100 \mathrm{~h}$. Before characterization, the aged samples were ultrasonically cleaned in alcohol for $5 \mathrm{~min}$ and dried at $90{ }^{\circ} \mathrm{C}$ in a vacuum furnace for $6 \mathrm{~h}$ to get rid of the corrosive solutions. According to the hydrothermal ageing mechanisms $[6,8]$, the drying procedure rarely disturbed the phase transformation of the samples investigated due to very low concentration of 
hydroxyl groups and oxygen.

\subsection{Microstructure characterization}

Scanning electron microscopy (SEM, NovaNano-430FEG, FEI, Netherlands) was used to characterize the microstructure of fresh samples and aged samples. Overall porosity, pore size and pore size distribution of the samples were analyzed by the mercury intrusion method (Auto Pore IV 9500, USA). The local porosity, pore size and grain size of the samples were estimated by analyzing their SEM images by using Image J software (Image J-1.43, National Institutes of Health, US). The mean grain size was calculated from 150 grains.

\subsection{Quantitative phase measurements by XRD and confocal micro-Raman spectroscopy}

X-ray diffraction (X' Pert PRO MPD, Panalytical, Netherlands) using $\mathrm{Cu}-\mathrm{K}_{\alpha}$ radiation at $40 \mathrm{kV}$ and $40 \mathrm{~mA}$ was used for phase analysis. The samples used for XRD had eighteen 3Y-TZP hollow fiber membranes that were arranged side-by-side on metal stages by using the conductive tape. Each fiber investigated was $\sim 20 \mathrm{~mm}$ in length, $1.2 \mathrm{~mm}$ in the outer diameter and $0.7 \mathrm{~mm}$ in the inner diameter (shown in Fig.S1 of Supplementary material). XRD patterns were recorded on the surfaces of each sample in the $27 \sim 90^{\circ}(2 \theta)$ range with a scan speed of 2 s per step and a step size of $0.03^{\circ}$. The $m$ phase volume fraction was calculated by using the Garvie and Nicholson's equation [22] as modified by Toraya et al. [23]. Detection depth for the transformed zirconia is $\sim 5 \mu \mathrm{m}$ in a non-destructive way using XRD (incidence beam angle was $\left.5^{\circ}\right)[6,12,24,25]$.

The $m$ phase volume fraction of the aged 3Y-TZP HFM was also estimated by using confocal micro-Raman spectroscopy. In order to avoid introducing extra $\mathrm{m}$ phase grains by the fracturing, sectioning and polishing steps, the machined samples were annealed for $0.5 \mathrm{~h}$ at the temperature that is $50{ }^{\circ} \mathrm{C}$ lower than the corresponding sintering temperature [6]. All Raman spectra were collected at room temperature using a single mono chromator $(\lambda=532 \mathrm{~nm}, \mathrm{~T}-64000$, Jobin-Ivon/Horiba Group, 
Kyoto, Japan) equipped with a nitrogen-cooled $1024 \times 256$ pixels CCD camera (CCD-3500V, Horiba Ltd., Kyoto, Japan) with $0.5 \mathrm{~cm}^{-1}$ spectral resolution (1800 grooves/mm grating). The objective lens of $50 \times$ was used to reach the lateral resolution $(\sim 1.8 \mu \mathrm{m})$, and scanning step size of $2 \mu \mathrm{m}$ was used. The confocal probe configuration was calibrated for quantitatively determining the laser penetration depth in the porous 3Y-TZP hollow fiber membranes (shown in Fig.S2 of Supplementary material). For the first collection, the laser beam is focused on the specimen surface and then the specimen is progressively translated toward to the objectives, to displace the excitation and confocal volumes inside the material. According to this calibration, it was found that the most reliable measurement in assessing the actual fraction of transformed $m$ phase was obtained with the depth of $4 \sim 8 \mu \mathrm{m}$ which agreed with published data [26-28]. The Raman peaks integration time was $20 \mathrm{~s}$ with three successive measurements at each point. Each Raman line scan collected on the outer surfaces and cross sections of the samples consisted 10 points. The average values of the Raman line scans were used to calculate the corresponding $m$ phase amount. The $m$ phase amount was then calculated by using the equation (1) of Tabares et al. [26], which is updated and believed to be more accurate in the study of low-temperature degradation of Y-TZP materials.

$V_{\mathrm{m}}=\frac{I_{\mathrm{m}}^{180}+I_{\mathrm{m}}^{190}}{I_{\mathrm{m}}^{180}+I_{\mathrm{m}}^{190}+\mathbf{F}\left(I_{\mathrm{t}}^{147}+I_{\mathrm{t}}^{264}\right)}$

Where $I_{\mathrm{m}}^{180}, I_{\mathrm{m}}^{190}, I_{\mathrm{t}}^{147}$ and $I_{\mathrm{t}}^{264}$ refer to the integrated intensities of the monoclinic (m) and tetragonal $(t)$ peaks in the Raman spectra at $180 \mathrm{~cm}^{-1}, 190 \mathrm{~cm}^{-1}, 147 \mathrm{~cm}^{-1}$ and $264 \mathrm{~cm}^{-1}$, respectively. $F$ is the factor required to convert the Raman intensities to the XRD intensities of the reference material; it was close to a constant value of 0.32 [26].

The Raman peak intensity ratio $\mathrm{I}_{307} / \mathrm{I}_{465}$ of pure tetragonal YSZ is always larger than 1.0. Therefore, the ratio less than 1.0 indicates the presence of the $c$ phase, owing to the Raman peak position at $\sim 465 \mathrm{~cm}^{-1}$ of tetragonal and cubic phase overlapping each other [29]. Accordingly, the semi-quantitative assessment of the relative abundance of each phase $\left(f_{\mathrm{t}}\right.$ and $\left.f_{c}\right)$ can be made using the relative intensities of the 
Raman peaks $\sim 307 \mathrm{~cm}^{-1}$ and $\sim 465 \mathrm{~cm}^{-1}$, listed in Table 1. The temperature dependence of $f_{\mathrm{c}}$ cited from literature [29-34] was also summarized in the Table 1. The Raman peaks positions and intensities were obtained by fitting the raw spectra collected with mixed Gaussian/Lorentzian curves (using Labspec 5.0, Horiba/JobinYvon, Kyoto, Japan).

Table 1 The cubic phase volume fraction $\left(f_{\mathrm{c}}\right)$ of samples sintered at different temperatures were evaluated by XRD using the Garvie and Nicholson's equation [22], and estimated by micro-Raman using the ratios of the intensities of the Raman peaks $\sim 307 \mathrm{~cm}^{-1}$ and $\sim 464 \mathrm{~cm}^{-1}$ [29].

\begin{tabular}{|c|c|c|c|c|c|c|c|c|}
\hline \multirow{3}{*}{$\begin{array}{l}\text { Temperatur } \\
\text { e } \\
\left({ }^{\circ} \mathrm{C}\right)\end{array}$} & \multicolumn{5}{|c|}{ XRD } & \multicolumn{3}{|c|}{ Raman } \\
\hline & \multicolumn{5}{|c|}{$\begin{array}{l}\text { Calculated by using Garvie and } \\
\text { Nicholson's equation }{ }^{[22]}\end{array}$} & \multicolumn{3}{|c|}{$\mathbf{I}_{307} / \mathbf{I}_{465}$} \\
\hline & $\begin{array}{l}\text { This } \\
\text { work }\end{array}$ & $\operatorname{Re}_{f[30]}$ & $\operatorname{Ref} f^{[31]}$ & $\operatorname{Ref} f^{[32]}$ & $\operatorname{Ref} f^{[33]}$ & $\begin{array}{l}\text { This work } \\
\text { surface }\end{array}$ & cross-section & Refs \\
\hline 1100 & 0 & - & - & & 8 & 0.48 & 0.95 & - \\
\hline 1150 & 0 & 12 & - & & - & 0.50 & 0.95 & $1.36^{[30]}$ \\
\hline 1200 & 0 & - & - & & 20 & 0.51 & 0.93 & $1.23^{[34]}$ \\
\hline 1250 & 0 & 22.5 & - & & - & 0.51 & 0.94 & - \\
\hline 1300 & 0 & - & 4.7 & 12.5 & 26 & 0.51 & 0.94 & $1.1^{[29]}$ \\
\hline 1400 & 9.5 & - & 9.1 & 15 & 40 & 0.55 & 0.89 & $1.1^{[34]}$ \\
\hline 1500 & 20.6 & - & 30.5 & 18 & - & 0.51 & 0.89 & $1.35^{[29]}$ \\
\hline
\end{tabular}

\subsection{Measurement of the residual stresses by confocal micro-Raman spectroscopy}

The highest reliability peak for stress assessment in a (monoclinic) tetragonal zirconia polycrystal is located at $\sim 465 \mathrm{~cm}^{-1}$ [26-28]. For the partly transformed zirconia, the $\sim 480 \mathrm{~cm}^{-1}$ peak and $\sim 508 \mathrm{~cm}^{-1}$ peak that partly overlap the most reliable peak of the tetragonal phase, and all the other peaks of the monoclinic phase are less reliable in stress assessment than the tetragonal peaks [28]. In order to minimize the interference from the two overlapping peaks of $\sim 480 \mathrm{~cm}^{-1}$ and $\sim 508 \mathrm{~cm}^{-1}$, the experimentally collected spectra were deconvoluted into three sub-peaks (shown in Fig.S3 of Supplementary material). The evaluation of stresses by confocal microRaman spectroscopy relies on the measurement of the shift of spectral lines relative to their unstrained state by using the equation (2) $[26,35,36]$ : 
$\sigma=\frac{1-v E}{\Pi E_{0}} \Delta v$

where $\Delta v$ is the Raman peak shift, $\sigma$ is the trace of the spatial average stress tensor, $\Pi$ is the piezospectroscopic constant which is $2.01 \mathrm{~cm}^{-1} / \mathrm{GPa}$ for the $465 \mathrm{~cm}^{-1}$ peak [37]. The objective lens $50 \times$ associated with a laser spot size of $\sim 1.8 \mu \mathrm{m}$ was used in the peak shift measurement in order to avoid the influence of the roughness on the fractured surfaces. $E_{0}$ and $E$ are the ideal elastic modulus of the dense materials and the real elastic modulus of the probed position, respectively. The following expression is employed the most frequently to describe the relationship between elastic modulus and porosity $(P)[38]$ :

$E=E_{0}\left(1-1.9 P+0.9 P^{2}\right)$

The Poisson's ratio of solid 3Y-TZP $v_{0}$ is 0.3 . Taking into account influence of porosity $(P)$, shape and orientation of the pores on elastic modulus, the effective Poisson's ratiov is given by the following equation $v=v_{0}-0.094 P$ which is derived from the overlapping spherical pores model [39].

Therefore, the Eq. (2) can be rewritten as following:

$\sigma=(0.3483+0.047 P) \times\left(1-1.9 P+0.9 P^{2}\right) \Delta v$

where $P$ is the 2D image porosity, which was estimated from SEM images with the area of $5 \times 5 \mu \mathrm{m}^{2}$ by using Image $\mathrm{J}$ software. Uncertainty of the image method depends on the SEM image contrast and observer's bias. In order to reduce the uncertainty, two independent groups were designed to calculate porosity by using the local image method. Each $P$ was the averaged porosity estimated from 5 probing areas that having a similar morphology. Final $P$ was an average value of porosities from the two independent measurement groups.

\section{Results}

The 3Y-TZP HFM samples have a special sandwich structure that was induced by the phase inversion process [1], as shown in Fig.1 (a)-(b). Higher temperature substantially promoted densification, and slightly accelerated grain growth, as shown 
in the SEM images of Fig.1 (c)-(d), where the samples were respectively sintered at $1100{ }^{\circ} \mathrm{C}$ and $1250^{\circ} \mathrm{C}$. The morphologies of the outer surface and the wall of fingerlike pores of the 1100-HFM looked quite similar, displaying a very fine-grained and homogeneous packing. For the 1250-HFM, the outer surface was of tetragonal $(t)$ phase grains; in contrast, the surface of a finger-like pore was composed of $t$ phase grains and some of large cubic (c) phase grains with diameters of $2.0 \sim 3.8 \mu \mathrm{m}$.

\subsection{Residual stresses of fresh 3Y-TZP HFM}

To avoid the interference from composition difference, the 3Y-TZP powders undergoing the same thermal treatments were used as the reference samples for residual stresses calculation. The residual stresses were calculated by using the Raman peak shifts and Eq. (4), shown in Fig.2. The solid symbols (red and blue) at the left of the figure represented the stresses measured on the outer surface, while the rest data measured on the cross sections of the samples. The outer surfaces of the $3 \mathrm{Y}$-TZP HFM sintered at $1100{ }^{\circ} \mathrm{C}$ and $1250{ }^{\circ} \mathrm{C}$ were under compressive stresses, corresponding to $-335 \mathrm{MPa}$ and $-100 \mathrm{MPa}$, respectively. Measured residual stresses on the cross section of the fresh 1100-HFM samples were in a range of $-38 \mathrm{MPa} \sim$ $335 \mathrm{MPa}$. By comparison, the measured residual stresses of the fresh 1250-HFM were lower, which fluctuated in a range of $63 \mathrm{MPa} \sim-100 \mathrm{MPa}$.

\subsection{Tetragonal phase stability}

XRD patterns and micro-Raman spectra in Fig.3 (a) and Fig.3 (b) show that fresh 3Y-TZP HFM samples were of tetragonal phase. Fig.3 (c) shows the $m$ phase amount as a function of the ageing time. The $m$ phase amount cannot be detectable before 22 $\mathrm{h}$ of ageing, and that showed a time dependent trend after the $22 \mathrm{~h}$. The $m$ phase amount reached the maximum values $(1.0 \sim 5.0$ vol \%) when the ageing time approached $100 \mathrm{~h}$, occurring in the aged 1250-HFM. After $100 \mathrm{~h}$ hydrothermal ageing, the monoclinic $(m)$ grains and tetragonal $(t)$ grains coexisted in the aged samples.

The $m$ phase amount as a function of the ageing time was also were examined by 
micro-Raman, as shown in Fig.3 (d). As expected, the transformation rate of the 1250-HFM was fastest than those samples sintered at lower temperatures, and the maximum amount of $m$ phase was $45 \pm 1.5 \mathrm{vol} \%$ after the $100 \mathrm{~h}$ ageing. Although sintering temperature and ageing time dependences of the $t-m$ phase transformation determined by both confocal micro-Raman spectroscopy and XRD were similar, the $m$ phase amount measured by micro-Raman was 1 order of magnitude higher than those evaluated by XRD. Furthermore, the characteristic peaks of $m$ phase of 3Y-TZP HFM aged $8 \mathrm{~h}$ were visible in the Raman spectra, while were absent in the XRD patterns.

Fig. 4 shows the $m$ phase amount as a function of the membrane thickness for the $100 \mathrm{~h}$ aged samples (1100-HFM and 1250-HFM). The SEM image inset of Fig.4 (a) demonstrates a schematic representation of the grid over which confocal microRaman spectra were collected (the details can be found in the Experimental section). Overall, higher amount of $m$ phase was found in the $100 \mathrm{~h}$ aged 1250-HFM compared with the $100 \mathrm{~h}$ aged 1100-HFM, which agreed with the tendency shown in Fig.3 (d). The $m$ phase and its maximum amount randomly scattered over the fractured crosssection of the aged samples rather than progressively decreasing from the outer surface as reported in literature [7-12, 23-26]. Moreover, compared with the probe positions $(1,2,3,5,6$ and 9) having uniform porosity and homogenous microstructure (Fig.4 (c)), the interface transition positions $(0,4,7,8$ and 10) had dramatic changes in the porosity and pore size (corresponding to Fig.4 (b)) and preferentially achieved high $m$ phase amounts.

The probed volume of each point by using the micro-Raman spectroscopy (50× objective) is $\sim 10 \mu \mathrm{m}^{3}$, therefore which represents a local analysis. To estimate the phase transformation over the whole aged samples representatively, polished oblique planes $\left(\sim 2.5 \times 10^{5} \mu \mathrm{m}^{2}\right)$ of the $100 \mathrm{~h}$ aged samples were used, as shown in Fig.5 (a). In order to avoid introducing extra $m$ phase grains by the sectioning and polishing 
steps, the as-polished samples were annealed for $0.5 \mathrm{~h}$ at the temperature that is $50{ }^{\circ} \mathrm{C}$ lower than the corresponding sintering temperature [6]. Fig.5 (b)-(e) show that the porosity varied amongst the four typical layers. 500 positions were selected randomly over the oblique plane, including 250 points at the wall surface of finger-like pores (corresponding to the yellow points) and the rest points (corresponding to the black points) locating beneath the wall layers, as shown Fig.5 (f). The statistical histograms of $m$ phase distribution of Fig.5 (g)-(i) implied that the $m$ phase appeared both on the wall surface and the subsurface of the wall layer of the finger-like pores of the samples, while the subsurface of the wall layer (namely, the interface transition position) had high probability to achieve maximum amount of $m$ phase compared with other layers.

Fig.6 (a)-(b) show the micro-Raman mappings of $m$ phase distribution at the outer surface and the inner surface of the 1250 -HFM aged $100 \mathrm{~h}$. The outer surface and inner surface both had discontinuous $m$ phase grains, and the latter had higher $m$ phase amount. Fig.6 (c) shows the $m$ phase distribution around a finger-like pore of the sample's polished cross-section (see optical image of Fig.6 (d)). The highest $m$ phase amount appeared at the subsurface layer (corresponding to the yellow spots and red spots), located at $2.0 \sim 4.0 \mu \mathrm{m}$ depth from the wall surface, which was consistent with the statistical data of maximum fraction of the $m$ phase shown in Fig.5.

\subsection{Morpology and microstructure of the aged 3Y-TZP HFM}

Fig.7 (a)-(b) show average grain size of tetragonal grains and porosity difference as a function of the sintering temperature of the 3Y-TZP HFM. The free surfaces (including the outer surfaces and the surfaces of finger-like pores) had faster grain growth compared with the subsurface layer (for instance, the sponge-like layer), and the grain size difference was dramatically enlarged by the sintering temperature. The average size of tetragonal grains of the surfaces of the finger-like pores monotonically increased from $130 \pm 10 \mathrm{~nm}$ to $515 \pm 35 \mathrm{~nm}$ with the sintering temperature, evaluated by 
using 150 grains from SEM images. The average size of tetragonal grains of spongelike layer monotonically increased from $117 \pm 17 \mathrm{~nm}$ to $189 \pm 32 \mathrm{~nm}$ with the sintering temperature. Stress free sintering of the free surfaces of 3Y-TZP HFM precursors caused the unexpected grain growth [40]. The porosity and pore size distribution of the fresh and $100 \mathrm{~h}$ aged $3 \mathrm{Y}$-TZP HFM samples sintered at different temperatures were measured by using the mercury intrusion porosimeter, as shown in Fig.7(c)-(d). The porosity of the fresh samples monotonically decreased with sintering temperature, and the 1250-HFM achieved the minimum porosity (47.5\%). It was also found that the $100 \mathrm{~h}$ hydrothermal ageing hardly changed the overall porosity, but substantially changed pore size distribution of the 1100-HFM sample. The pores with $\sim 680 \mathrm{~nm}$ diameter of the 1100-HFM disappeared, while new pores with size of $\sim 430$ nm appeared.

The $8 \mathrm{~h}, 22 \mathrm{~h}$ and $50 \mathrm{~h}$ ageing treatments did not change the outer surface texture of the 3 Y-TZP HFM, and no $m$ phase grain/nucleus was observed. After $100 \mathrm{~h}$ ageing, a few of elongated $m$ phase grains span on several $t$ phase grains of the aged samples, as shown in Fig.8. The $m$ phase grains with the diameter spanning $1.1 \sim 2.5 \mu \mathrm{m}$ embedded into $t$ phase matrix $(\sim 190 \mathrm{~nm})$ of the aged 1100-HFM. For the 1250-HFM aged $100 \mathrm{~h}$, the $m$ phase grains were also clearly visible with typical surface uplifts appearing on the $t$ phase grains $(\sim 530 \mathrm{~nm})$. The three $m$ phase grain growth types reported in the dense Y-TZP (including internal growth, external growth and needle growth) were also observed in the aged 1250-HFM [10]. The three grain growth types are labeled as M-I, M-II and M-III in the SEM image of Fig.8 (c). A number of isolated martensite needles with size of $0.9 \sim 1.7 \mu \mathrm{m}$ (estimated from 50 grains) were found at the free surfaces, which were not reported in the uniform 3Y-TZP bulks hydrothermally aged [7-12, 23-27].

\subsection{Microcracking and its orientation}


Microcracks were observed on the wall surfaces of the finger-like pores of the aged 1250-HFM that having the highest $m$ phase amount, as shown in Fig.9 (a). The $\sim 5 \mu \mathrm{m}$ in length microcracks went along grain boundaries of the sample, and short microcracks $(\sim 1 \mu \mathrm{m})$ propagated into cubic phase grains of the transformed zones. By contrast, no microcrack was observed in the $100 \mathrm{~h}$ aged 1100 -HFM. It is necessary to emphasize that the microcracking orientation of the investigated samples was mostly perpendicular to the free surface (see Fig.9 (d)), while microcracks were always parallel to the free surface of the samples, reported in published articles $[6,8,9,12]$. However, the microcracks produced in both the dense 3 Y-TZP samples $[6,8,9,12]$ and our porous $3 \mathrm{Y}$-TZP membranes follow one rule that is they are more or less perpendicular to the orientation of a martensite plate (maximum strain elongation direction).

\section{Discussion}

\subsection{The difference in $m$ phase amount determined by XRD and micro-Raman}

In comparison to the $m$ phase amount of $1.0 \sim 5.0 \mathrm{vol} \%$ of the outer surface of the aged 3Y-TZP HFM analyzed by XRD, the $m$ phase amount $(30 \sim 45$ vol\%) determined by micro-Raman spectra is significantly lower, as shown in Fig.3. Using different equations developed from the intensities of the Raman peaks could give different results. The $m$ phase amount was also calculated by using the other wellaccepted equation proposed by Clarke and Adar [41], although the equation is believed to underestimate the $m$ phase fraction of aged femoral heads and dental ceramics. By using the Clarke and Adar's equation [41], the maximum amounts of $m$ phase of the aged 1100-HFM and the aged 1250-HFM were $20.1 \mathrm{vol} \%$ and $30.2 \mathrm{vol} \%$ (shown in Fig.S4 of Supplementary material), respectively, which were still one order of magnitude higher than the values determined by XRD. The order of magnitude difference in the $m$ phase amount determined by the two characterization methods could be due to the difference in the probed volume, depending on the penetration depth and probe diameter. In our study, the penetration depth of XRD and 
micro-Raman spectroscopy is in the $4.0 \sim 8.0 \mu \mathrm{m}$, while the probe diameter of the former is in the range of millimeters and the latter is $\sim 1.8 \mu \mathrm{m}$. The probed volume issue of XRD measurement is negligible for dense and homogeneous 3Y-TZP samples $[11,12,26,27]$, however, for measuring the cross-section of the porous $3 \mathrm{Y}$ TZP membranes, the probe size is too big to identify $m$ phase concentration gradient in micrometer scale. In the context of large radiated volume of the XRD examination, the $m$ phase fraction is of small in proportion to the total volume of the sample detected. XRD analysis gives an averaged phase composition, while micro-Raman measurement is a kind of local characterization, the result of which is close to the data determined by XRD when the samples are homogenous. The 3Y-TZP HFM sample was lack of microstructure homogeneity because of containing both micrometer sized pores and hundreds of micrometer sized finger-like pores. The asymmetrical microstructure could be responsible to the large concentration deviation of $m$ phase when micro-Raman method was applied to evaluate the aged samples. Besides, grain morphologies of the samples aged $100 \mathrm{~h}$ showed the classic appearance of the Y-TZP materials aged at the early stage $[6,10,12]$. XRD measurement is believed to be not capable to detect $m$ phase nucleated at the early stages of the phase transformation compared with the micro-Raman spectroscopy [12, 24-27].

\subsection{Nucleation rate and growth rate of the $m$ phase}

From SEM observations and micro-Raman mappings, the highest amounts of $m$ phase occurred at the interface transition layers (for instance, the subsurface of the wall layer of finger-like pores) that having large change in porosity and pore size. Thickness of the interface transition layer was approximately $0.5 \sim 1.0 \mu \mathrm{m}$ and $2.0 \sim$ $4.0 \mu \mathrm{m}$ for the fresh 1100-HFM and fresh 1250-HFM, respectively, estimated from the SEM images shown in Fig.1 and Fig.5. The maximum values of $m$ phase occurred below the wall surface of the finger-like pore, located at $2.0 \sim 4.0 \mu \mathrm{m}$ depth, which suggested that the phase transformation rate of the surface was lower than that of the subsurface.

For dense 3Y-TZP ceramics, only the exposed surfaces have access to moisture, 
therefore, the phase transformation proceeds from the grain boundaries to the grain centers subsequently. Consequently, there is a gradual decrease in the $m$ phase amount with depth into the samples $[6,9,12,24,27]$; otherwise, the transformed surface is also probably be a fully transformed layer over the sample, with the constant amount of $m$ phase (saturation amount) [24, 27]. However, for the 3Y-TZP HFM sample that having high porosity and interconnected pores/tunnels, the free surfaces and subsurface layers have equal access to moisture, as confirmed by Fig.7(c). Although the ageing performance of the 3Y-TZP HFM showed in Fig.3 conformed the classic Mehl-Avrami-Johnson equations (MAJ) [6, 12], statistical analysis of Fig.5 (g)-(i) showed that the highest amounts of $m$ phase were found around the interface transition layers that having substantial change in porosity and pore size. The strong correlation between the $\mathrm{m}$ phase distribution and the microstructure of the aged samples was also confirmed by SEM observations and micro-Raman mappings. The discrepancy in the $m$ phase concentration raises two doubts as follow: where the initial $t-m$ phase transformation in the 3Y-TZP HFM samples starts from and how the phase transformation zone propagates.

Theoretically, the $t-m$ phase transformation thereupon can start at any layers if the free energy $\left(\Delta G_{t-m}\right)$ of which is satisfied $[6,36]$. The $\Delta G_{t-m}$ takes into account all contributions relevant for the $\mathrm{t}-\mathrm{m}$ transformation thus consists of three factors $[4,20$, 32, 39]:

$$
\Delta G_{t-m}=\Delta G_{t-m}^{\text {Surf }}+\Delta G_{t-m}^{\text {Chem }}+\Delta G_{t-m}^{\text {strain }}
$$

where the $\Delta G_{t-m}^{\text {Surf }}$ term is dependent of the size of the particles involved in the $t-m$ phase transformation, and an increase in grain size would promote the $m$ phase nucleation. The $\Delta G_{t-m}^{\text {Chem }}$ term is obtained from the chemical potentials imposed by zirconia and its stabilizers. $\Delta G_{t-m}^{\text {Strain }}$ is the contribution from strain and its energy. The $m$ phase amount of hydrothermally aged 3 Y-TZP materials is both dependent of the nucleation rate and of the growth rate $[6,9,10]$. The three terms will be discussed 
to clarify their contributions to the nucleation rate and grain growth rate of $m$ phase in the 3 Y-TZP HFM aged.

\section{(1) Effect of the grain size}

The $m$ phase preferentially nucleates at grain boundaries of large tetragonal grains, therefore, reducing the average grain size of 3Y-TZP ceramics has a beneficial influence on the stability of tetragonal grains $[6,9,15]$. The 1100 -HFM with small grains achieved the lower $m$ phase fraction in comparison to the 1250-HFM sample having large grains. Fig.7 shows the surfaces of the samples had larger grain size than the other interface transition layers owing to fast grain growth induced by stress free sintering [42]. However, statistical analysis in the Fig.5 and Fig.6 revealed that the maximum values of the $m$ phase presented at the interface transition layers of the aged samples (the subsurface layers). Nucleation rate of monoclinic grain is more dependent on grain size compared with growth rate in view of thermodynamics $[6,8]$. Therefore, the results suggested that the $\Delta G_{t-m}^{\operatorname{Surf}}$ term was not a critical factor for the $m$ phase amount of the 3 Y-TZP HFM aged.

\section{(2) Effect of the Tetragonal-Cubic phase separation}

The tetragonal-cubic $(t-c)$ dual-phase separation was experimentally observed on the surface wall of finger-like pores of the 1250-HFM (see Fig.1(f)). The dependence of $c$ phase fraction $(f \mathrm{c})$ of the fresh 3Y-TZP HFM on sintering temperature was estimated by using XRD and micro-Raman, as shown in Fig.10. The $c$ phase corresponding peak (400) was observed in the sample sintered at $1400{ }^{\circ} \mathrm{C}$ for $2 \mathrm{~h}$ and the $f_{\mathrm{c}}$ was estimated to be $9.5 \mathrm{vol} \%$ by XRD. The $f_{\mathrm{c}}$ increased with increasing temperature, and attained $20.6 \mathrm{vol} \%$ at $1500{ }^{\circ} \mathrm{C}$. The intensity ratio of $\mathrm{I}_{307} / \mathrm{I}_{465}$ of raw $3 \mathrm{Y}$-TZP powder was 0.95 . The decreases in the $\mathrm{I}_{307} / \mathrm{I}_{465}$ ratio can been used as an indicator of the $f_{\mathrm{c}}$ increase [29]. The increasing behavior of $f_{\mathrm{c}}$ is a result of the tetragonal-cubic phase separation during sintering process [38]. Data in Table1 shows that the $\mathrm{I}_{307} / \mathrm{I}_{465}$ ratio significantly decreased with sintering temperature from $1100{ }^{\circ} \mathrm{C}$ 
to $1500{ }^{\circ} \mathrm{C}$. The $\mathrm{I}_{307} / \mathrm{I}_{465}$ of the sintered samples' surfaces varied in the range of 0.48 0.55, while that determined on the subsurface layers varied from 0.89 to 0.95 (see Table 1). The $I_{307} / I_{465}$ ratio difference between the two layers indicated that the surfaces had higher $f_{\mathrm{c}}$ than the subsurface layers, which agreed with the SEM observation where a few of cubic grains presented in the surface, but were absent in the subsurface layer. The 3Y-TZP samples prepared by using thermal spraying and furnace sintering methods are composed of pure tetragonal phase. Phase separation by diffusion of $\mathrm{Y}^{3+}$ and oxygen vacancies occurs, creating a dual-phase composite consisting of a mixture of tetragonal phase and cubic phase with increasing temperature and dwelling time [6, 30-33]. This occurs concurrently with any grain growth. As discussed in the grain size effect, the densely packed particles theoretically enhanced densification and grain growth that was experimentally observed at free surfaces of 3Y-TZP HFM samples, whereupon the fast grain growth consequently accelerated the cubic grains appearing early [40, 42, 43]. However, there was no visible cubic grains in the subsurface layers of both 1100-HFM and 1250-HFM (seen Fig.9). Second, $f_{c}$ of the surfaces was higher than that of the subsurface layers of the sintered samples; thereby, yttrium segregation could be more severe at grain boundaries of the samples' surface rather than the subsurface layers. The significance of the $t-c$ dual-phase separation into yttrium-rich cubic and yttriumpoor tetragonal phases is that the yttrium-depleted tetragonal grains are unstable and serve as preferential nucleation sites for the $t-m$ transformation [6]. The yttrium segregation can promote the $t-m$ transformation owing to that leading the $\Delta G_{t-m}^{C h e m}$ term being more negative. As a result, $m$ phase amount would be high around the $t-c$ dual-phase layers (for instance, free surfaces of the aged samples), which conflicted with our SEM observations and Raman mappings of $m$ phase distribution. Thus, we inferred that the $t-c$ phase separation had no significant contribution to the $m$ phase growth rate.

\section{(3) Effect of residual stresses}


In cases of the 3Y-TZP HFM, thermal residual stresses were a result of the strain mismatch during sintering, induced by the asymmetric microstructure composed of porosity gradient and finger-like pores. Both measurements (see Fig.2) and the theoretical prediction [38] demonstrated that the surfaces with higher density were more likely to undertake residual compressive stresses, while the interface transition layers (e.g. subsurface, sponge-like layer and inner surface) preferentially undertook residual tensile stresses. The $m$ phase nucleation can be triggered only if the residual tensile stress that governing $\Delta G_{t-m}^{\text {Strain }}$ term is greater than the critical stress (500 $700 \mathrm{MPa})[17,41,44]$. The residual tensile stress is even less than the critical stress could also effectively promote the growth rate of $m$ phase grains once the nucleation started $[4,6,8]$. To provide a simple and clear interpretation how the residual stresses affect the hydrothermal phase transformation of the 3Y-TZP HFM samples, a bi-layer model was used as shown in Fig.11. For the fresh 1250-HFM, the average residual compressive stresses of the outer surface fluctuated in the range of $99.5 \pm 14 \mathrm{MPa}$ (see solid spot of Fig.2), then its adjacent subsurface layer would under tensile stress in the same value for static equilibrium. According to the mathematic model and experimental data described in the article [10], the residual stress at the interface layer is approximate 2 times that at the outer surface measured by using micro-Raman. Thus, the residual stress from the outer surface to the adjacent subsurface layer of the fresh 1250 -HFM can be theoretically predicted semi-quantitatively and presented by solid lines in Fig.11. Residual compressive stresses/tensile stresses existed in the outer surface/the subsurface layer, both with maximum values near the interface between the two layers. The residual stresses at the interface and the adjacent subsurface layer were also measured experimentally by using micro-Raman (see the data points of Fig.11). The residual tensile stress was found in the adjacent subsurface layer, but the stress values did not meet the theoretical predictions. The experimental data deviated from theoretical value can be attributed to the limited position accuracy of the microRaman spectroscopy, because the laser spot size of $1.8 \mu \mathrm{m}$ (using a $50 \times$ optical lens) is too large for the outer surface layer with $\sim 2.0 \mu \mathrm{m}$ thickness. Considering the 
theoretical prediction and experimental results, it can be concluded that the stresses near the interface on both sides were $174 \sim 222 \mathrm{MPa}$ in magnitude, but with opposite signs (compressive in the outer surface and tensile in the subsurface layer). Residual tensile stress of $\sim 200 \mathrm{MPa}$ will effectively double the growth rate of $m$ phase grains $[8,17]$, therefore the residual tensile stress at the subsurface layer of the 1250 -HFM can promote the growth rate of $m$ phase at grain boundaries.

\subsection{Possible mechanism for hydrothermal ageing of the 3Y-TZP HFM}

Fig.12 (a) presents the proposed a nucleation and growth mechanism of 3Y-TZP HFM samples hydrothermally aged, based on oxygen vacancy annihilation [6-8]. The microcracks produced are more or less perpendicular to the orientation of a martensite plate (maximum strain elongation direction). Therefore, the shear strain associated with the $t-m$ phase transformation in the in-plane direction that will release as microcracks form, as shown the step (i) and step (ii) in Fig.12 (a). Once the martensite plate has nucleated, the phase transformation will spread throughout the whole grain (within the layer and depth) until is stopped by the pores of the lower layer that act as a barrier for the transformation propagation in-depth because of higher strain tolerance $[11,37]$. By contrast, the phase transformation will extend to the neighboring grains of the outer surface, because the induced tensile stress $(\sigma)$ and strain $(\varepsilon)$ in turn favor its further transformation, as outlined in the step (iii) and (iv) of Fig.12 (a). After the subsurface layer reached $m$ phase saturation level, the transformation then proceeds to the outer surface and bulk with a very low rate after $22 \mathrm{~h}$. The proposed phase transformation mechanism for the aged 1250-HFM is also applicable to the other aged samples investigated.

In summary, the nucleation rate depends on the grain size and the yttrium oxide segregation thus has higher possibility to occur at the exposed surfaces (including the outer surface, inner surface and the wall surface of finger-like pores), while the $m$ phase amount is mainly determined by the growth rate of monoclinic grains. The growth rate was critically influenced by thermal residual stress induced by the sintering shrinkage mismatch [40]. The thermal residual stress at the interface 
between the outer surface and the subsurface provides an extra the driving force required for the phase propagation. Thus, the thermal residual stress accelerates the growth rate of grain boundaries of the subsurface. The porous samples possibly have higher strain tolerance in horizontal direction compared with the dense 3Y-TZP bulks, which caused the microcracks preferred to forming in the vertical direction.

This hypothesis properly explained that the $m$ phase was absent on the outer surface of the 1250-HFM aged for less than $100 \mathrm{~h}$. Moreover, the residual compressive stresses within the outer surfaces of the fresh 3 Y-TZP HFM explained the observation of the isolated needle-like $m$ phase grains (like M-III in Fig.8 (c)). The compressive stresses can suppress the propagation of the habit plane in the near surface layer, in a similar manner to the action of oxide layers in the case of martensitic transformation in metals [45-47]. Thus, needle-like $m$ phase grains formed at outer surfaces instead of fully transformed monoclinic grains (for instance M-I and M-II in Fig.8 (c)). Fig.12 (b) shows distribution of the corresponding residual stresses over the membrane thickness of 1100-HFM and 1250-HFM before and after the $100 \mathrm{~h}$ ageing. The newly formed $m-\mathrm{ZrO}_{2}$ grain is constrained by the surrounding untransformed material, whereas its push against the surrounding materials (the untransformed $\mathrm{t}-\mathrm{ZrO}_{2}$ grains) gives origin to a small tensile stress. When more grains transform to monoclinic, they are less constrained and the compressive stress diminishes gradually, whereas they put in larger tensile stress retained in the $\mathrm{t}-\mathrm{ZrO}_{2}$ grains. Roughly, an increase of $10 \%$ of $\mathrm{m}-\mathrm{ZrO}_{2}$ increases the tensile stress in $\mathrm{t}-\mathrm{ZrO}_{2}$ by $250 \mathrm{MPa}$ [8]. It was found that thermal residual tensile stresses in the order of MPa magnitude remained in the aged 1100HFM, while thermal residual compressive stresses remained in the aged 1250-HFM because of microcracks (see Fig.9) releasing the tensile stresses. The thermal residual tensile stresses were the result of the $t-m$ phase transformation of the aged samples, occurring at early and moderate stages without microcracking $[9,12]$. It is worthwhile know that the values of residual stresses in partly transformed areas of the aged samples can be obtained but, despite the high intrinsic reliability of the $\sim 465 \mathrm{~cm}^{-1}$ tetragonal peak for stress assessment, these values may not represent the actual residual stress magnitude because of overlapping of the $480 \mathrm{~cm}^{-1}$ monoclinic peak is 
not negligible.

\section{Conclusions}

The sintered 3Y-TZP hollow fiber membranes (3Y-TZP HFM), having asymmetric microstructure with large porosity gradient and finger-like pores, were utilized as the model samples to investigate hydrothermal ageing behaviors of highly porous tetragonal zirconia. The asymmetric microstructure causing constraint sintering that promoted uneven grain growth and $t-c$ phase separation, observed at the free surfaces. Additionally, local thermal residual stresses were detectable in the sintered samples. After hydrothermal ageing of $100 \mathrm{~h}$, the maximum amount of $m$ phase highly probably occurred at the subsurface (approximate $2.0 \sim 4.0 \mu \mathrm{m}$ away from the free surface) according to the evidences of the micro-Raman mapping. Correlation between the $m$ phase and the thermal residual stress implied that the residual stresses of $174 \sim 222 \mathrm{MPa}$ in the interface transition layer probably accelerate the monoclinic grain growth rate at grain boundaries of the subsurface layer. The findings suggest that reducing thermal residual tensile stresses can improve resistance of highly porous zirconia membranes for hydrothermal ageing.

\section{Acknowledgements}

The authors acknowledge the Research Fund of National Natural Science Foundation of China [No. 51402058] and the fund of Shanghai Committee of Science and Technology [No. 14ZR1422900]. Dr. F.W. Guo thanks CNPEC for the financial support.

\section{Data availability}

The raw data required to reproduce these findings are available to download from supplementary information.

\section{References}


[1] S. Liu, X. Tan, K. Li, Preparation and characterization of inorganic hollow fiber membranes, J. Membrane Sci. 188 (2001) 87-95.

[2] L. Liu, X. Tan, S. Liu, Yttria Stabilized Zirconia Hollow Fiber Membranes, J. Am. Ceram. Soc. 89 (2006) 1156-1159.

[3] W. Li, J.J. Liu, C.S. Chen, Hollow fiber membrane of yttrium-stabilized zirconia and strontium-doped lanthanum manganite dual-phase composite for oxygen separation, J. Membrane Sci. 340 (2009) 266-271.

[4] E. Merlani, C. Schmid, V. Sergo, Residual stresses in alumina/zirconia composites: effect of cooling rate and grain size. J. Am. Ceram. Soc. 84 (2001) 2962-2968.

[5] R.C. Garvie, The occurrence of metastable tetragonal zirconia as a crystallite size effect, J. Phys. Chem. 69 (1965) 1238-1243.

[6] J. Chevalier, L. Gremillard, A. V. Virkar, D. R. Clarke, The tetragonalmonoclinic transformation in zirconia: Lessons learned and future trends, J. Am. Ceram. Soc. 92 (2009) 1901-1920.

[7] F. Zhang, M. Batuk, J. Hadermann, G. Manfredi, A. Mariën, K. Vanmeensel, M. Inokoshi, B.V. Meerbeek, I. Naert, Effect of cation dopant radius on the hydrothermal stability of tetragonal zirconia: grain boundary segregation and oxygen vacancy annihilation. Acta Mater. 106 (2016) 48-58.

[8] V. Lughi, V. Sergo, Low temperature degradation-ageing-of zirconia: a critical review of the relevant aspects in dentistry, Dental Mater. 26 (2010) 807-820.

[9] A.A. Nogiwa-Valdez, W.M. Rainforth, P. Zeng, I.M. Ross, Deceleration of hydrothermal degradation of 3Y-TZP by alumina and lanthana co-doping. Acta Biomater. 9 (2013) 6226-6235.

[10]S. Deville, G. Guénin, J. Chevalier, Martensitic transformation in zirconia Part II. Martensite growth, Acta Mater. 52 (2004) 5709-5721.

[11]V. Lughi, D.R. Clarke, Low-temperature transformation kinetics of electronbeam deposited 5 wt.\% yttria-stabilized zirconia, Acta Mater. 55 (2007) 20492055 .

[12]J.A. Muňoz-Tabares, E. Jiménez-Piqué, M. Anglada, Subsurface layer evaluation 
of hydrothermal degradation of zirconia, Acta Mater. 59 (2011) 473-484.

[13]Y.S. Kim, C.H. Jung, J.Y. Park, Low temperature degradation of yttria-stabilized tetragonal zirconia polycrystals under aqueous solutions, J. Nucl. Mater. 209 (1994) 326-331.

[14] V. Sergo, Room temperature ageing of laminate composites of alumina/3 mol\%yttria-stabilized tetragonal zirconia polycrystals, J. Am. Ceram. Soc. 87 (2004) 247-253.

[15]L. Hallmann, P. Ulmer, E. Reusser, M. Louvel, C.H.F. Hämmerle, Effect of dopants and sintering temperature on microstructure and low temperature degradation of dental Y-TZP-zirconia, J. Eur. Ceram. Soc. 32 (2012) 4091-4104.

[16]S. Deville, J. Chevalier, L. Gremillard, Influence of surface finish and residual stresses on the ageing sensitivity of biomedical grade zirconia, Biomater. 27 (2006) 2186-2192

[17]J. Li, L. Zhang, Q. Shen, T. Hashida, Degradation of yttria stabilized zirconia at $370 \mathrm{~K}$ under a low applied stress, Mater. Sci. Eng. A 297 (2001) 26-30.

[18]C. Mochales, A. Maerten, A. Rack, P. Cloetens, W.D. Mueller, P. Zaslansky, C. Fleck, Monoclinic phase transformation of zirconia-based dental prostheses, induced by clinically practiced surface manipulations, Acta Biomater. 7 (2001) 2994-3002.

[19]F. Guo, G. Wang, Z. Jiang, X. Zhao, P. Xiao, Growth of carbon nanofibers/tubes by an in-situ polymerization route without metal-catalyst, Carbon 100 (2016) 417-427.

[20]S.L. Low, S.L. Ong, H.Y. Ng, Characterization of membrane fouling in submerged ceramic membrane photobioreactors fed with effluent from membrane bioreactors, Chem. Eng. J. 290 (2016) 91-102.

[21]S.M. Ibrahim, H. Nagasawa, M. Kanezashi, T. Tsuru, Robust organosilica membranes for high temperature reverse osmosis (RO) application: Membrane preparation, separation characteristics of solutes and membrane regeneration, J. Membrane Sci. 493 (2015) 515-523.

[22]R.C. Garvie, P.S. Nicholson, Phase analysis in zirconia systems, J. Am. Ceram. 
Soc. 55 (1972) 303-305.

[23]H. Toraya, M. Yoshimura, S. Somiya, Calibration curve for quantitative analysis of the monoclinic-tetragonal $\mathrm{ZrO}_{2}$ system by X-ray diffraction, J. Am. Ceram. Soc. 67 (1984) 119-121.

[24]L. Gremillard, S. Grandjean, J. Chevalier, A new Method to Measure Monoclinic Depth Profile in Zirconia-Based Ceramics from X-Ray Diffraction Data, Int. J. Mater. Res. 1 (2010) 88-94.

[25]M. Keuper, K. Eder, C. Berthold, K.G. Nickel, Direct evidence for continuous linear kinetics in the low-temperature degradation of Y-TZP, Acta Biomater. 9 (2013) 4826-4835.

[26]J.A. Muñoz Tabares and M.J. Anglada, Quantitative Analysis of Monoclinic Phase in 3Y-TZP by Raman Spectroscopy, J. Am. Ceram. Soc. 93 (2010) 17901795.

[27]C. Wulfman, N. Djaker, M. Sadoun, M.L. Chapelle, 3Y-TZP In-Depth Phase Transformation by Raman Spectroscopy: A Comparison of Three Methods, J. Am. Ceram. Soc. 97 (2014) 2233-2240.

[28]G. Pezzotti, A.A. Porporati, Raman spectroscopic analysis of phasetransformation and stress patterns in zirconia hip joints. J. Biomed. Opt. 9 (2004) $372-384$

[29]Feng Zhang, Chih-Hao Chen, Jonathan C. Hanson, Richard D. Robinson, Irving P. Herman, and Siu-Wai Chan. Phase in Cera-Zirconia Binary Oxide $(1-\mathrm{x}) \mathrm{CeO}_{2-}$ ${ }_{\mathrm{x}} \mathrm{ZrO}_{2}$ nanoparticles: the effect of particle size. Journal of American Ceramic Society 89(2006) 1028-1036.

[30]Archana Loganathan and Ashutosh S. Gandhi. Effect of phase transformations on the fracture toughness of $t^{\prime}$ yttria stabilized zirconia. Materials Science \& Engineering A 556 (2012) 927-935.

[31]M. Inokoshi, F. Zhang, J. De Munck, S. Minakuchi, I. Naert, J. Vleugels, B. Van Meerbeek, K. Vanmeensel. Influence of sintering conditions on low-temperature degradation of dental zirconia. Dental materials 30 (2014) 669-678

[32] K. Matsui, H. Horikoshi, N. Ohmichi, M. Ohgai, Cubic-formation and grain- 
growth mechanisms in tetragonal zirconia polycrystal, J. Am. Ceram. Soc. 86 (2003) 1401-1408.

[33] Grain boundary segregation-induced phase transformation in yttria-stabilized Tetragonal zirconia polycrystal. Koji MaTsui, Nobukatsu Ohmichi, Michiharu Ohgai, Hidehiro Yoshida and Yuichi Ikuhara. Journal of the Ceramic Society of Japan 114(3) (2006) 230-237.

[34]Andi M. Limarga, Samuel Shian, Mor Baram, David R. Clarke. Effect of hightemperature aging on the thermal conductivity of nanocrystalline tetragonal ytttria-stabilized zirconia. Acta Mateterialia 60 (2012) 5417-5424.

[35]D. Liu, O. Lord, O. Stevens, P.E.J. Flewitt, The role of beam dispersion in Raman and photo-stimulated luminescence piezo-spectroscopy of yttria-stabilized zirconia in multi-layered coatings, Acta Mater. 61 (2013) 12-21.

[36]A. M. Limarga, R. Vaßen, and D. R. Clarke, Stress Distributions in PlasmaSprayed Thermal Barrier Coatings Under Thermal Cycling in a Temperature Gradient, J. Appl. Mech., 78[1] (2010) 011003- 011003-9.

[37]A. Portinha, V. Teixeira, J. Carneiro, M.G. Beghi, C.E. Bottani, N. Franco, R. Vassen, D. Stoever, A.D. Sequeira, Residual stresses and elastic modulus of thermal barrier coatings graded in porosity, Surf. Coat. Tech. 188-189 (2004) $120-128$.

[38]J. Luo and R. Stevens, Porosity-dependence of elastic moduli and hardness of 3Y-TZP, Ceram. Int. 25(1999) 281-286.

[39]A.P. Roberts, E.J. Garboczi, Elastic properties of model porous ceramics, J. Am. Ceram. Soc., 83 [12] (2000)3041-3048.

[40]T.T. Molla, D.K. Ramachandran, D.W. Ni, V. Esposito, F. Teocoli, E. Olevsky, R. Bjørk, N. Pryds, A. Kaiser, H.L. Frandsen, Modeling constrained sintering of bi-layered tubular structures, J. Eur. Ceram. Soc. 35 (2015) 941-950.

[41]D. R. Clarke and F. Adar, Measurement of the Crystallographically Transformed Zone Produced by Fracture in Ceramics Containing Tetragonal Zirconia, J. Am. Ceram. Soc., 65 [6] (1982)284-288.

[42]F. Wakai, F. Aldinger, Sintering through surface motion by the difference in 
mean curvature, Acta Mater. 51 (2003) 4013-4024.

[43]M. Colognaw and R. Raj, Surface diffusion-controlled neck growth kinetics in early stage sintering of zirconia, with and without applied DC electrical field, J. Am. Ceram. Soc. 94 (2011) 391-395.

[44]B.C. Mercer, J.R. Williams, D.R. Clarke, A.G. Evens, On a ferroelastic mechanism governing the toughness of metastable tetragonal-prime $\left(\mathrm{t}^{\prime}\right)$ yttriastabilized zirconia, Proc. R. Soc. A 463 (2007) 1393-1408.

[45]F.R. Chien, F.J. Ubic, V. Prakash, A.H. Heuer, Stress-induced martensitic transformation and ferroelastic deformation adjacent microhardness indents in tetragonal zirconia single crystals, Acta mater. 46 (1998) 2151-2171.

[46]S. Schmauder, U. Schubert, Significance of internal stresses for the martensitic transformation in yttria-stabilized tetragonal zirconia polycrystals during degradation, J. Am. Ceram. Soc. 69 (1986) 534-40.

[47]S. Lawson, Environmental Degradation of Zirconia Ceramics, J. Eur. Ceram. Soc. 15 (1995) 485-502. 


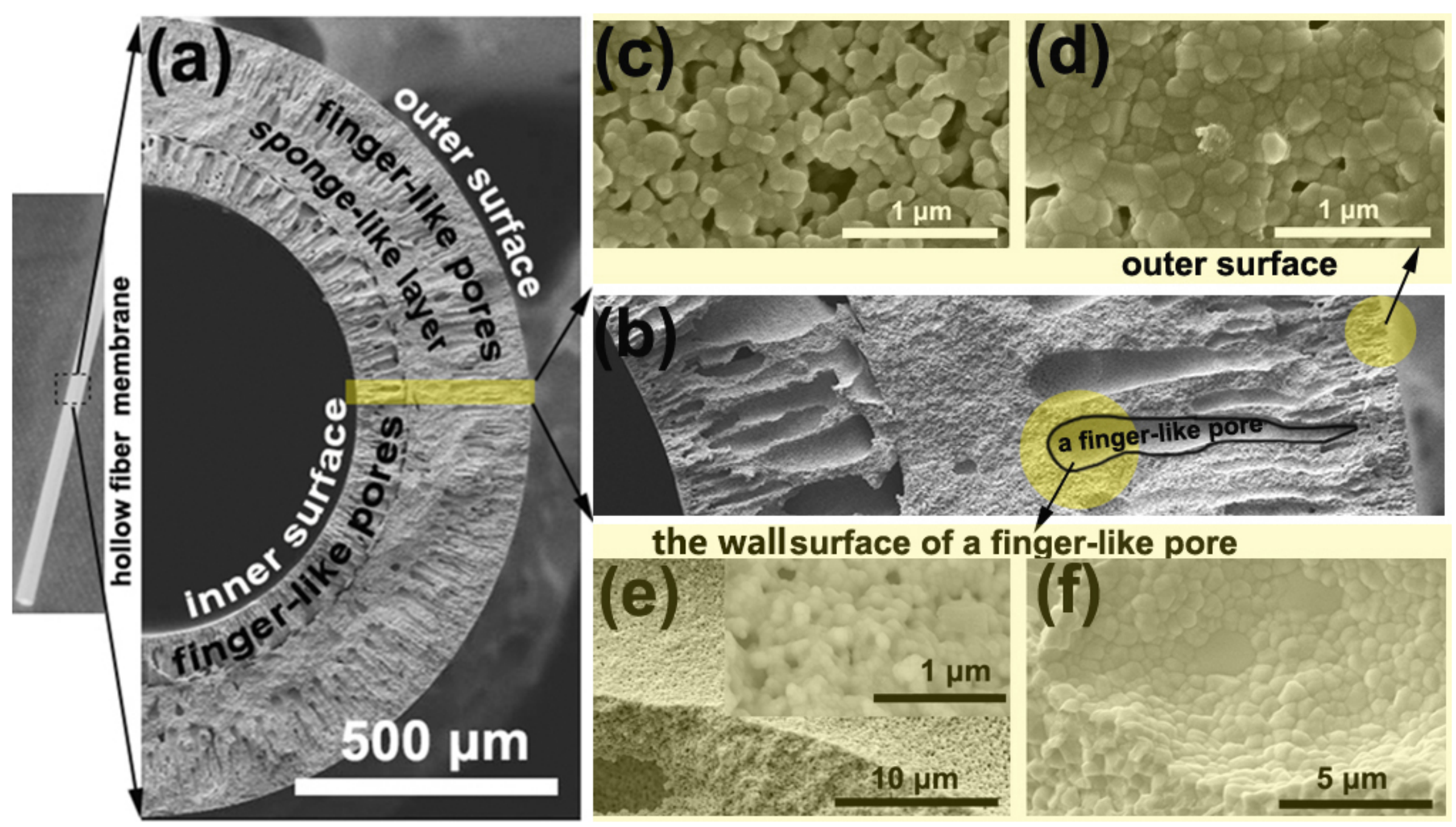

Fig.1 SEM images of a fresh 3Y-TZP HFM sintered: (a) the fractured cross section, (b) the enlarged image. The outer surface SEM images of the (c) 1100-HFM, and (d) 1250-HFM. The SEM images of the wall surface of a finger-like pore of the (e) 1100-HFM, and (f) 1250-HFM. 


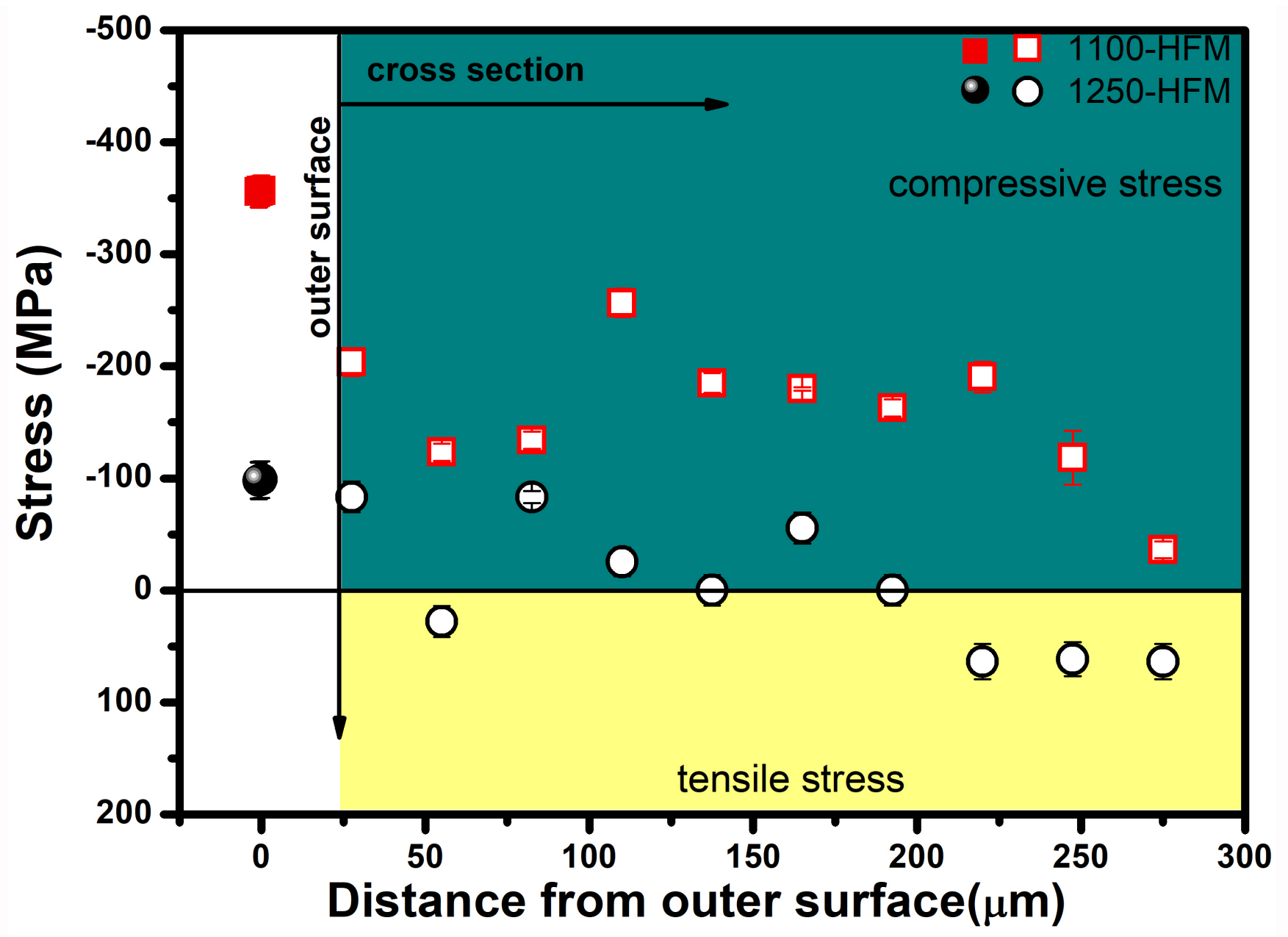

Fig.2 The residual stresses at the outer surface and throughout the cross section of the fresh 1100-HFM and 1250-HFM, respectively. The objective lens 50x associated with laser size of $\sim 1.8 \mu \mathrm{m}$ was used in the peak shift measurement to avoid roughness interference of fractured surfaces on the peak position accuracy. 

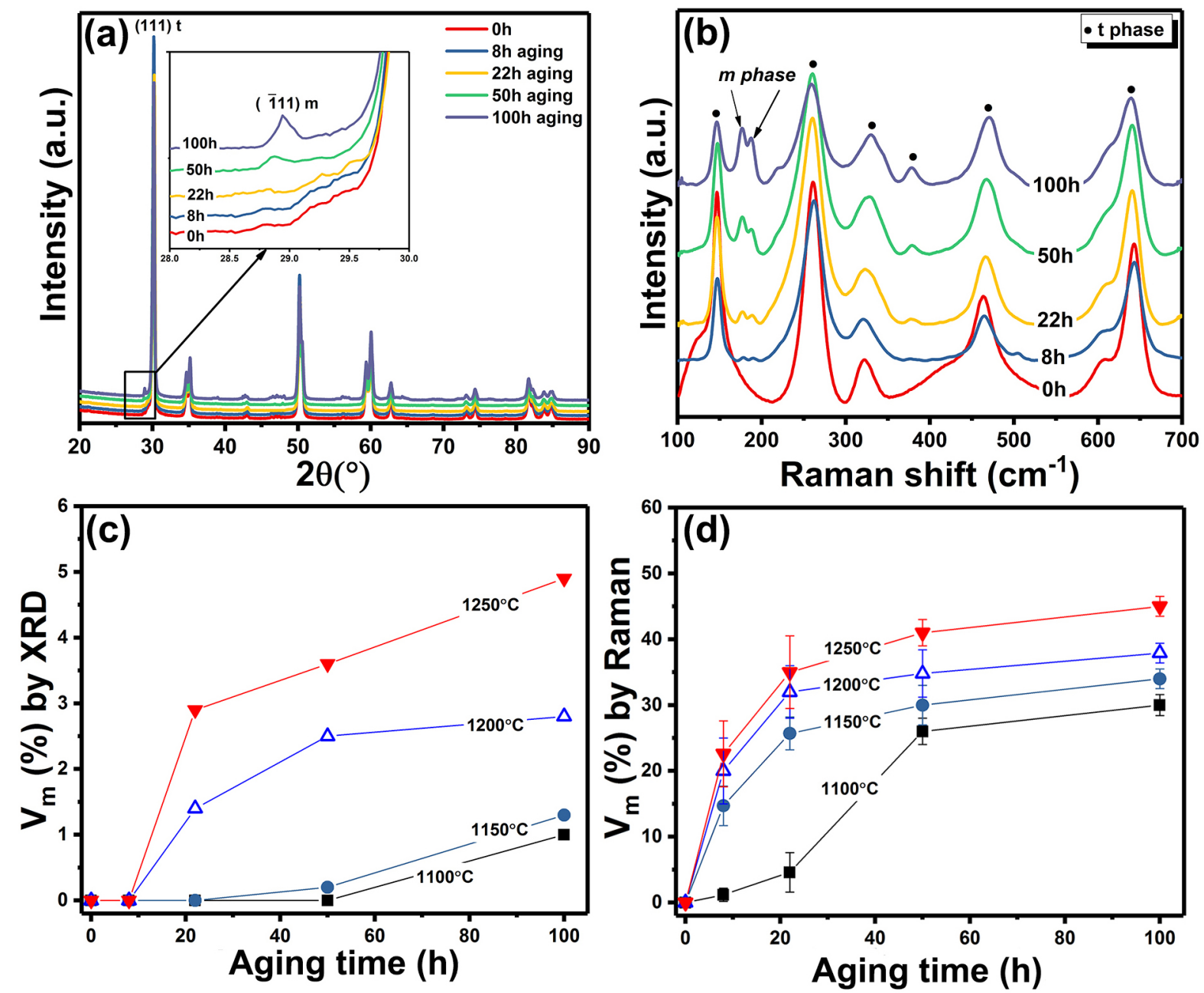

Fig.3 Effect of ageing time on (a) XRD patterns and (b) Raman shifts of the samples sintered for $4 \mathrm{~h}$ at $1100^{\circ} \mathrm{C}$. The $\mathrm{m}$ phase volume fraction as a function of the ageing time measured (c) by XRD and (d) by confocal micro-Raman spectroscopy on the outer surfaces of the aged $3 Y-T Z P-H F M$. The samples were sintered for $4 \mathrm{~h}$ at $1100^{\circ} \mathrm{C}, 1150^{\circ} \mathrm{C}, 1200^{\circ} \mathrm{C}$ and $1250^{\circ} \mathrm{C}$, respectively. The data errors in Fig.3(c) were less than $0.05 \mathrm{Vm} \%$. 


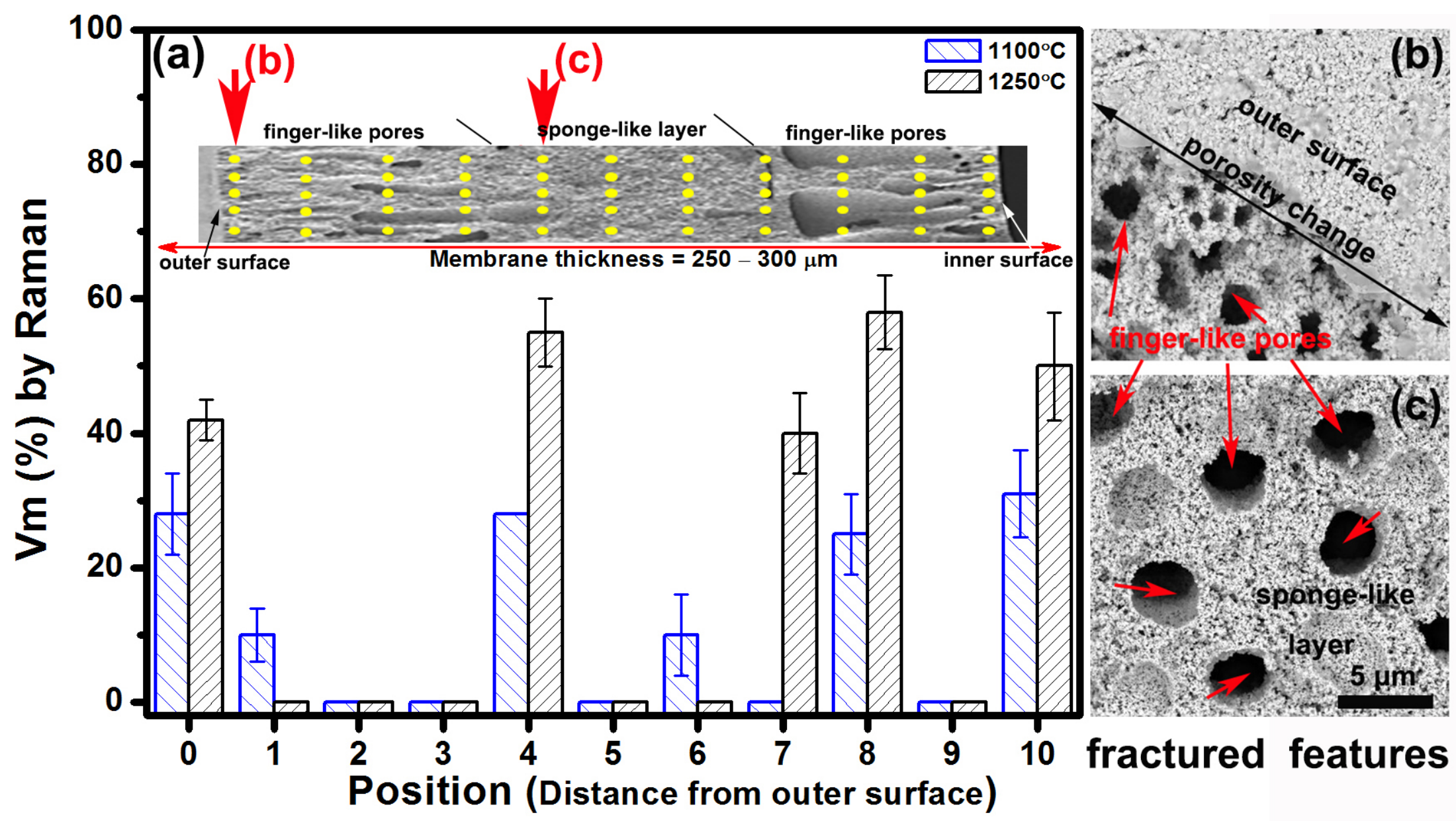

Fig.4 (a) The $m$ phase distribution across the fracture cross-section of the 1100-HFM and 1250-HFM aged for $100 \mathrm{~h}$, evaluated by using micro-Raman spectroscopy. The SEM images of the positions of the samples achieving (b) high $\mathrm{m}$ phase amount (corresponding to the interface transition positions $0,4,7,8$ and 10) and (c) low $\mathrm{m}$ phase amount (corresponding to the positions 1, 2, 3, 5, 6 and 9). The objective lens was $50 \times$ with a spot size of $1.8 \mu \mathrm{m}$, and the scanning step was $2.0 \mu \mathrm{m}$. 

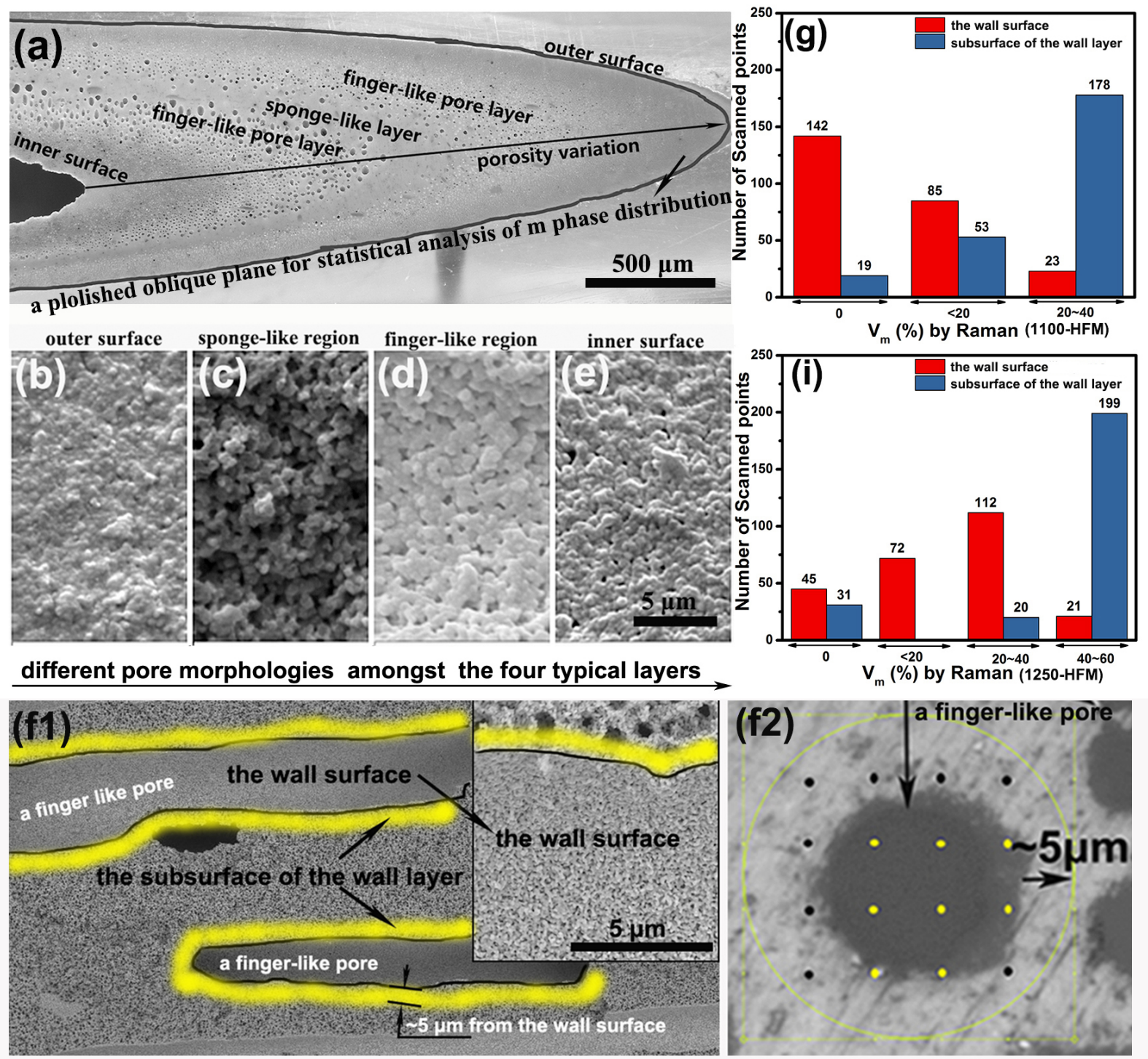

Fig.5 (a) The optical image of the polished oblique plane of the 1100-HFM used for the statistical analysis of $m$ phase distribution, showing pore size and shape changes amongst the outer surface, sponge-like layer, finger-like pore layer and the inner surface. SEM images of (b) the outer surface, (c) the sponge-like layer, (d) the finger-like pore layer and the (d) the inner surface of the sample. (f1) The SEM image illustration for the definitions of "the wall surface", "the subsurface of the wall layer of a finger-like pore" of the sample investigated. Statistical analysis of $m$ phase volume fraction measured on polished sections of ( $f 2$ ) the samples aged $100 \mathrm{~h}$ by using confocal micro-Raman spectroscopy. The statistical histograms of $m$ phase amount of the (g) 1100-HFM and (i) 1250-HFM, aged for $100 \mathrm{~h}$. The objective lens was 50x with a spot size of $1.8 \mu \mathrm{m}$ and the scanning step was $2 \mu \mathrm{m}$. Each sample collected 500 points. 

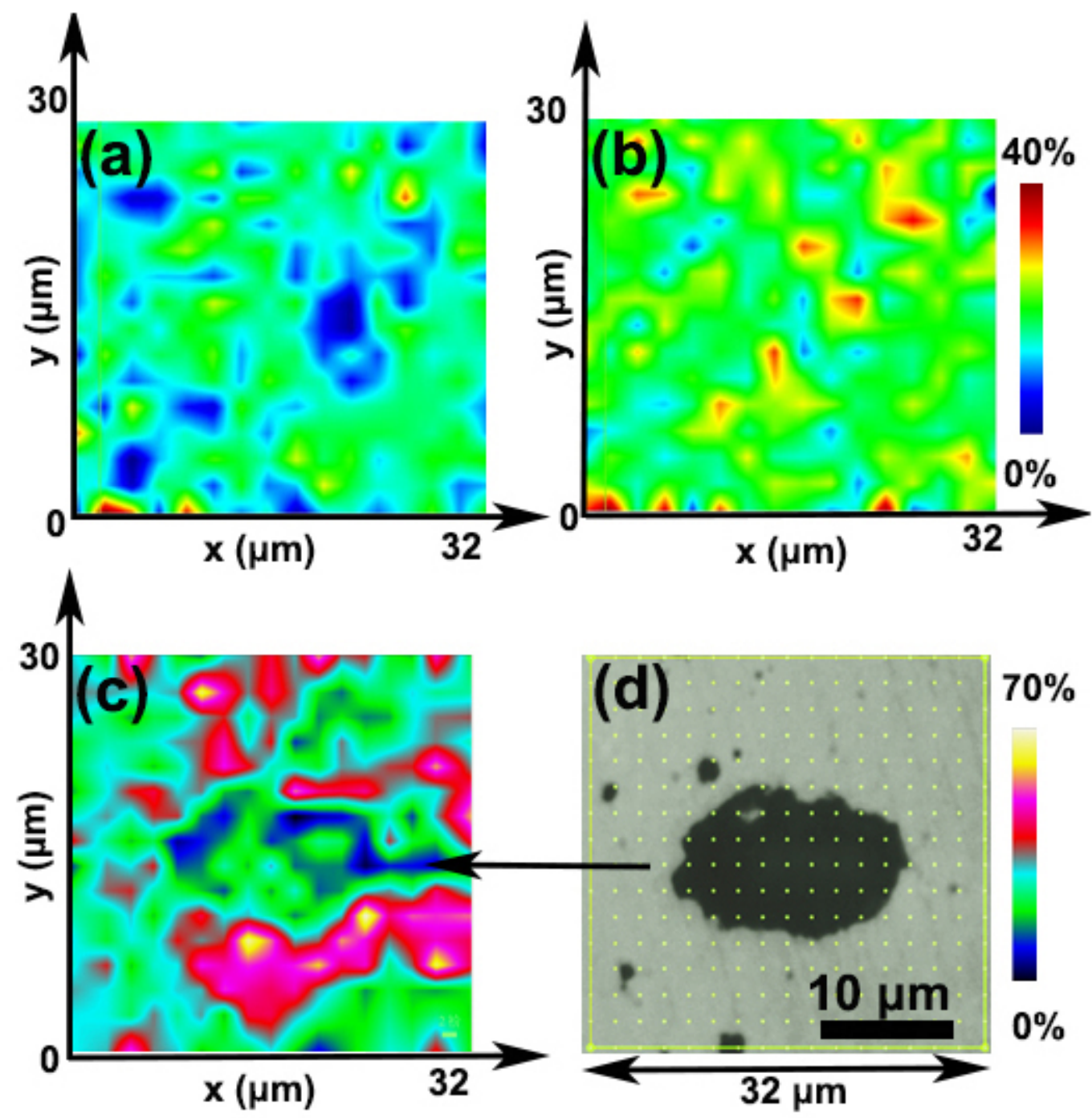

Fig.6 (a) Micro-Raman mappings of the $m$ phase distribution (a) at the outer surface, (b) at the inner surface, and (c) around a finger-like pore of the polished cross-section of the 1250-HFM aged $100 \mathrm{~h}$; (d) the corresponding optical image of the micro-Raman mapped area shown in Fig.6(c). The $m$ phase amount (calculated using Eq. (1)) was color-coded in images. The objective lens was $50 \times$ with a spot size of $1.8 \mu \mathrm{m}$ and the scanning step was $2 \mu \mathrm{m}$. 

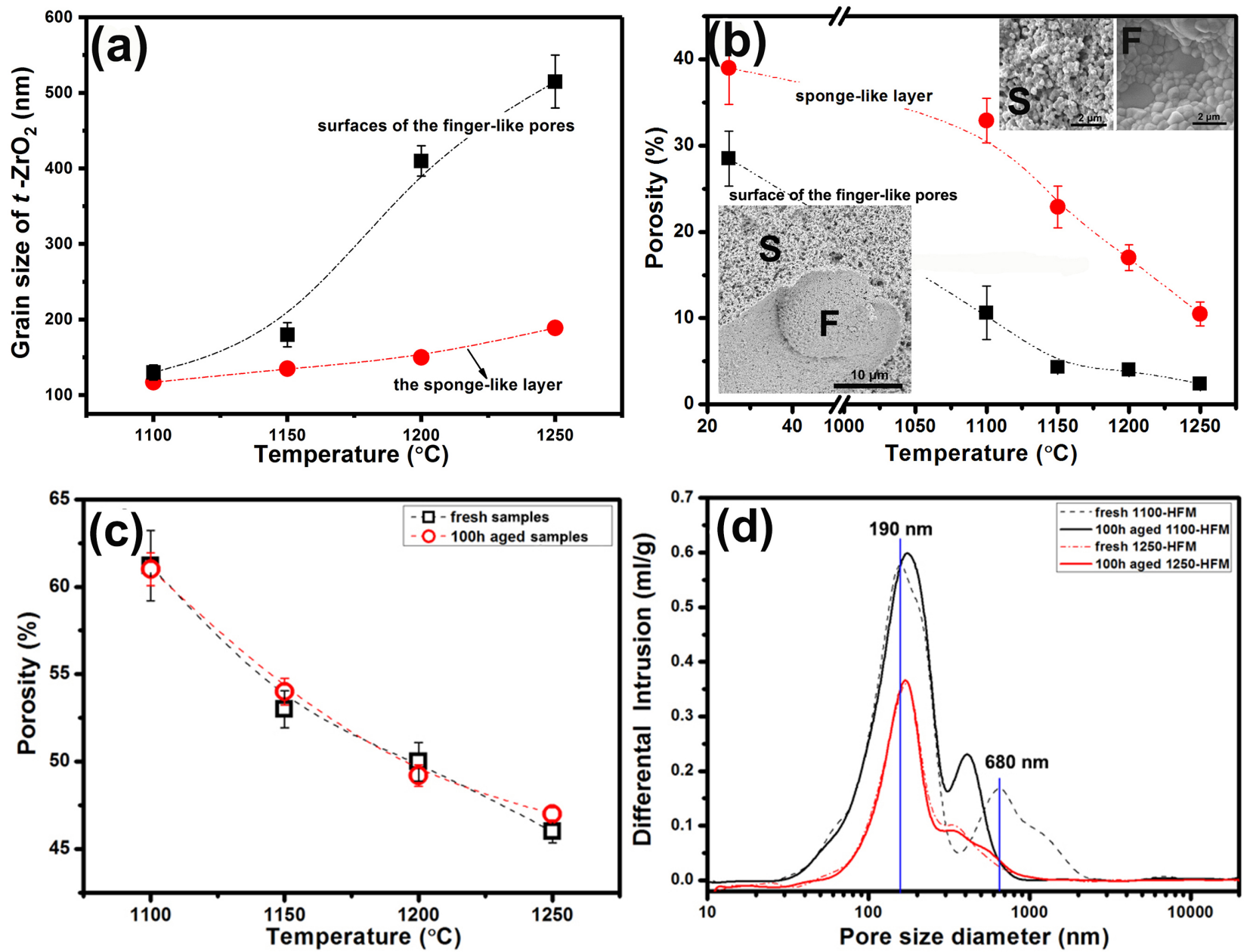

Fig.7 (a) Tetragonal grain size of 3Y-TZP-HFM samples as a function of sintering temperature, (b) porosity difference as a function of sintering temperature. The inset at the lower left represented the SEM image of the 1100-HFM sample, including the sponge layer (S) and the surface of finger like pores (F); the two insets at the top right showed $S$ and $F$ in the 1250-HFM sample, respectively. The average grain size was determined by the planimetric method. Change of (c) porosity and (d) the pore size distribution of the samples before and after the $100 \mathrm{~h}$ ageing. 

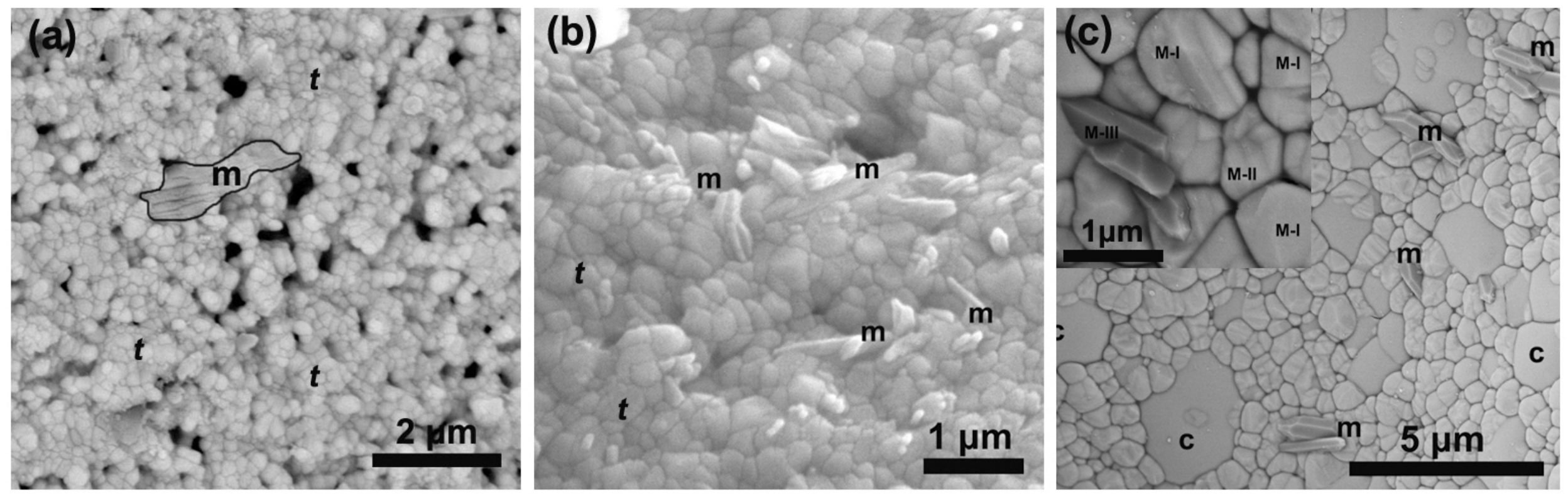

Fig.8 SEM/BSE images of the 100h aged 3Y-TZP HFM samples. (a)The outer surface of the aged 1100-HFM. (b) The outer surface and (c) the wall surface of a finger-like pore of the aged 1250-HFM. The $\mathrm{m}$, $\mathrm{t}$ and $\mathrm{c}$ represent monoclinic, tetragonal and cubic phase grain, respectively. 


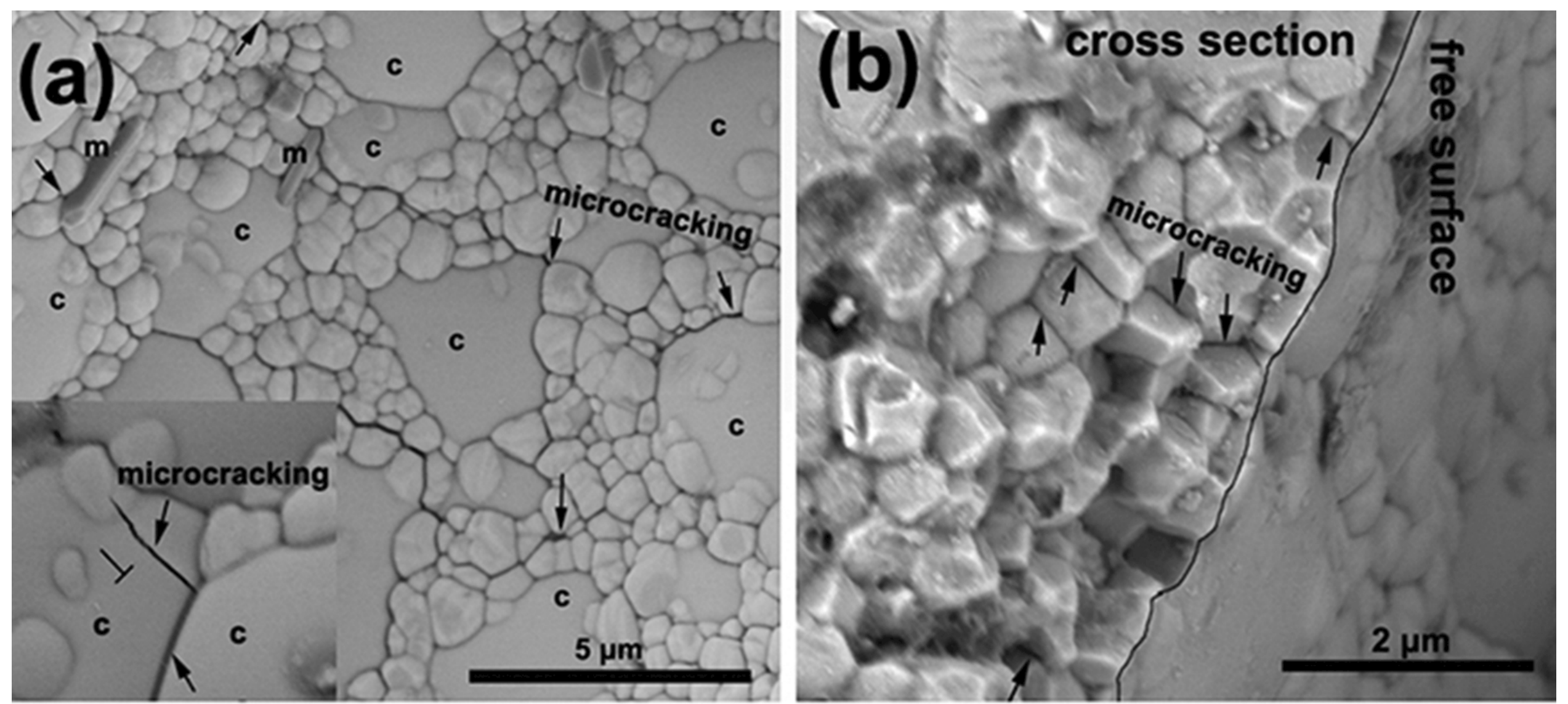

Fig.9 (a) Microcracks on the wall surface of a finger-like pore, (b) microcracks were perpendicular to the free surface. Arrows on the images indicate the microcracking location. 

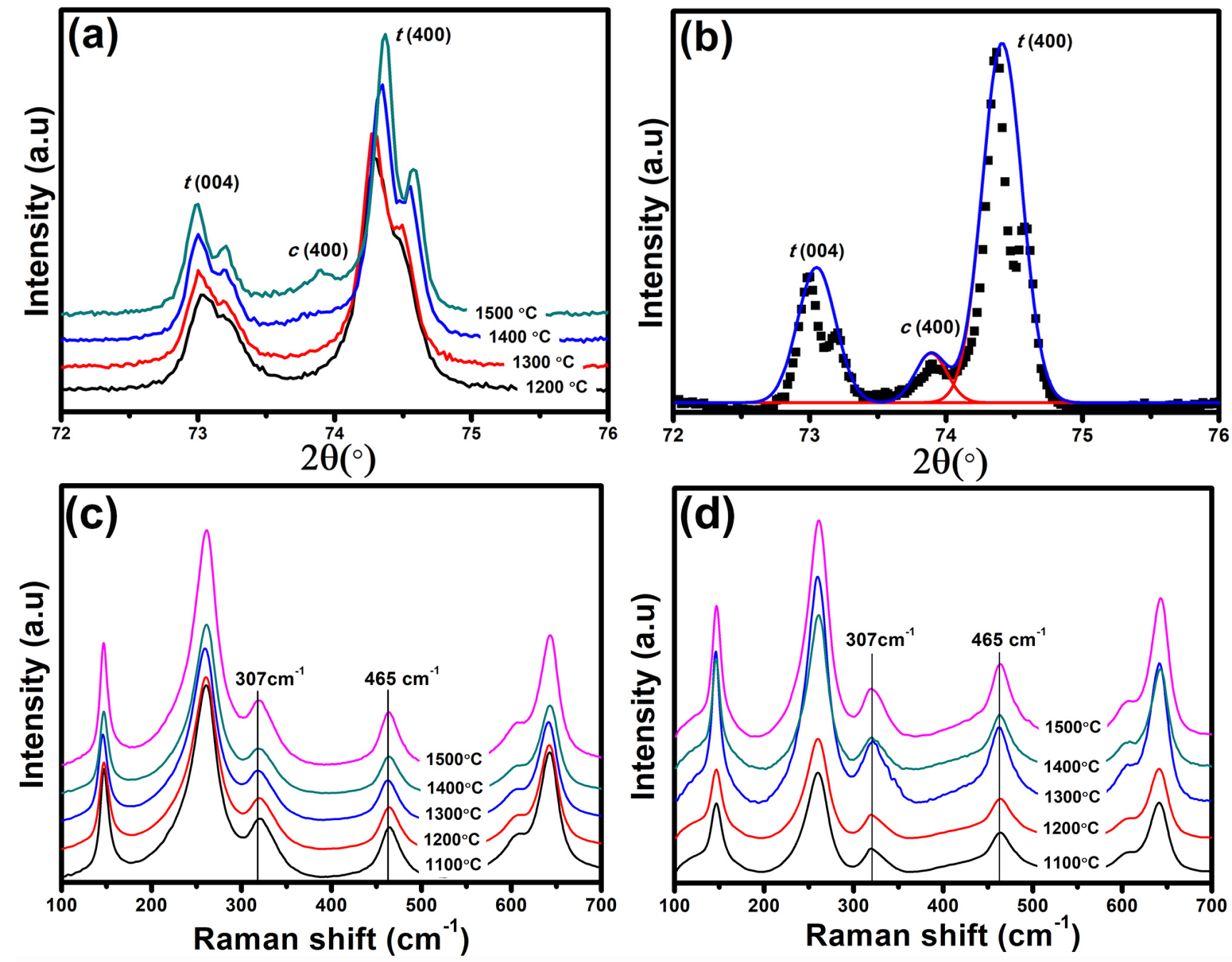

Fig.10 (a) XRD patterns of 3Y-TZP HFM samples sintered for $2 \mathrm{~h}$ at $1200^{\circ} \mathrm{C}$, $1300{ }^{\circ} \mathrm{C}, 1400^{\circ} \mathrm{C}$ and $1500^{\circ} \mathrm{C}$, respectively, (b) fitting peaks of the 3Y-TZP HFM sample sintered at $1500{ }^{\circ} \mathrm{C}$. Raman spectra of (c) sub-surface layers and (d) outer surfaces of $3 \mathrm{Y}$-TZP HFM samples sintered for $2 \mathrm{~h}$ at $1100{ }^{\circ} \mathrm{C}, 1200{ }^{\circ} \mathrm{C}$, $1300^{\circ} \mathrm{C}, 1400{ }^{\circ} \mathrm{C}$ and $1500{ }^{\circ} \mathrm{C}$, respectively. 


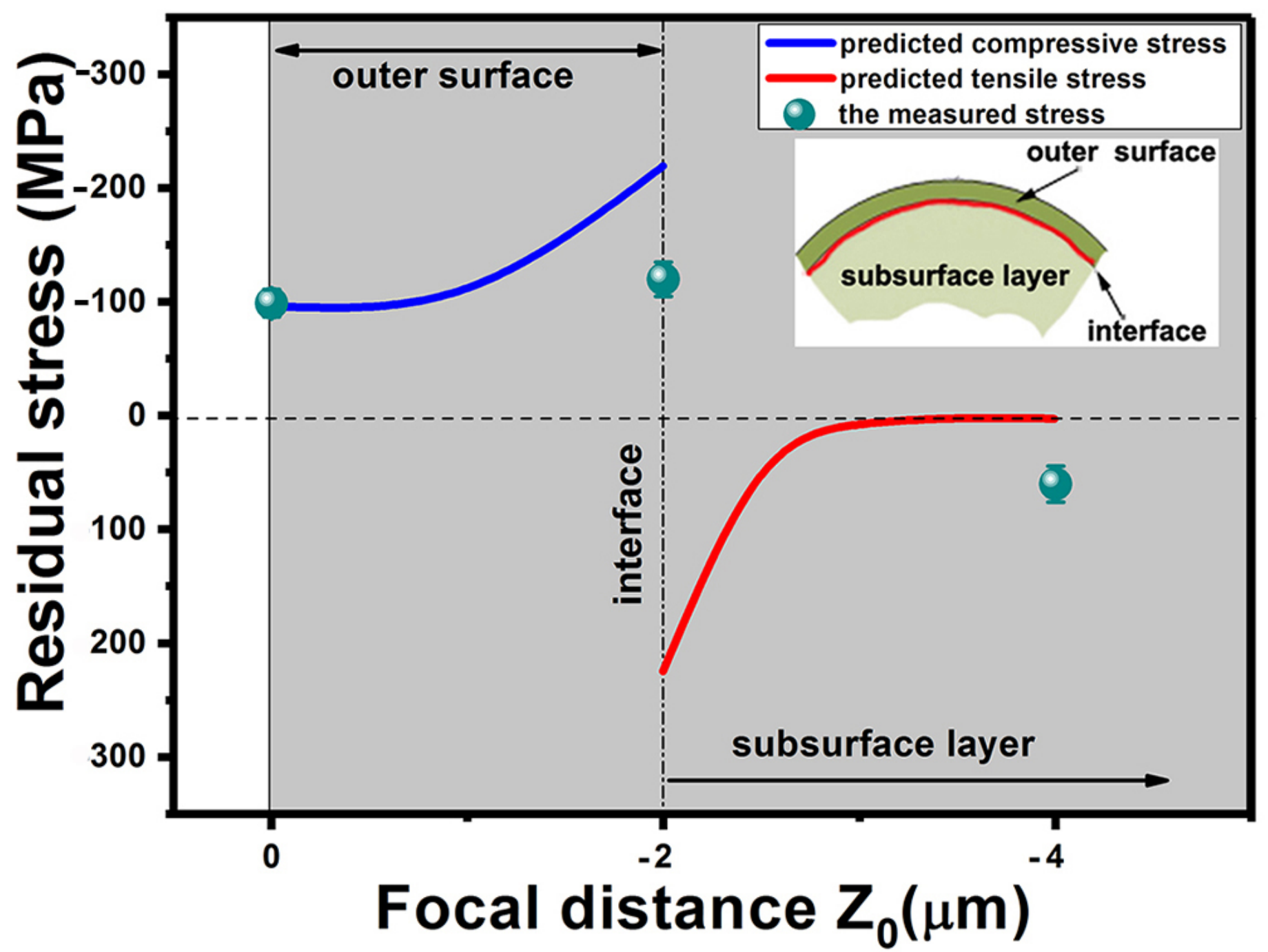

Fig.11 The dependences of residual stress on focal distance, $\mathrm{ZO}$, measured from the outer surface to $4 \mu \mathrm{m}$ depth by using confocal volume measurement (see the Experimental 2.5). The solid lines represent the theoretical stress distribution predicted according to the article [17]. 
(a)
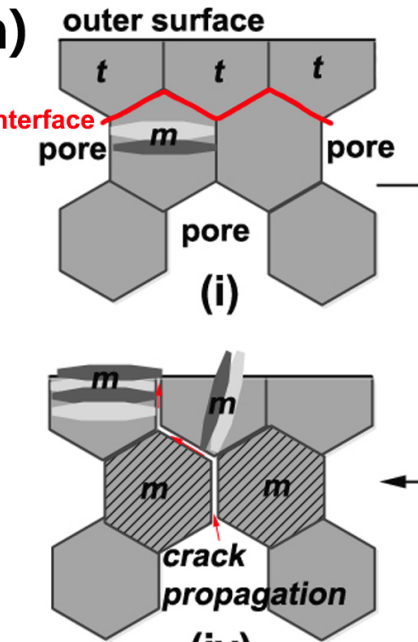

(iv)

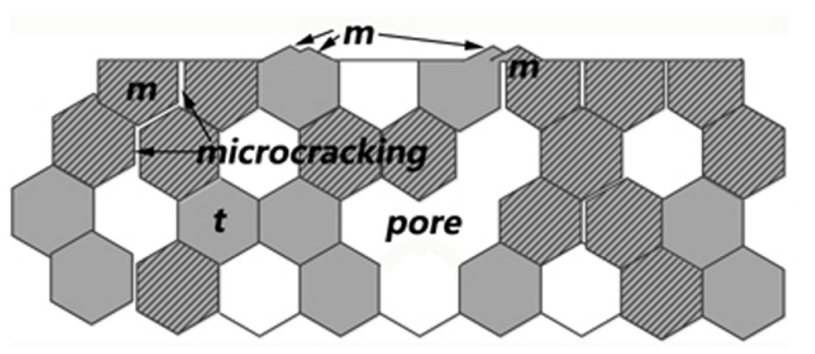

(v)
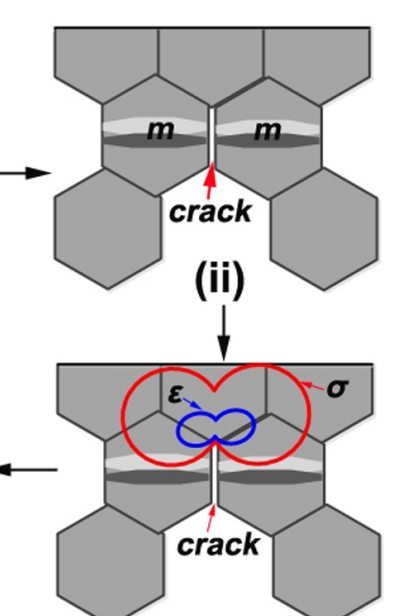

(iii)

(b)

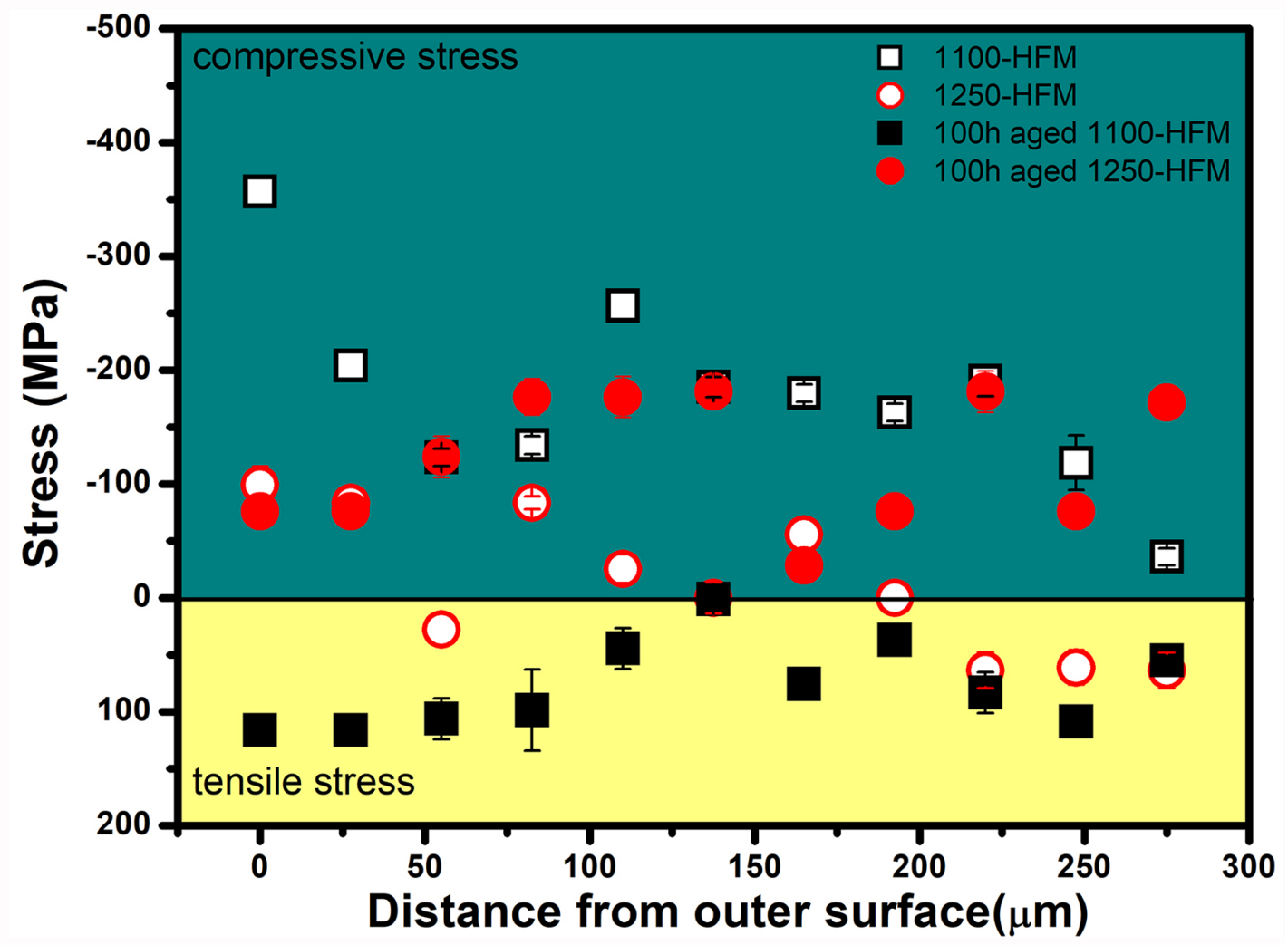

Fig.12 (a) A mechanism proposed for monoclinic (m) phase nucleation, propagation and microcracking. (i) Initial $m$ phase nucleation at grain boundaries of the subsurface,(ii) microcracks formation, (iii) the strain and stress affected zones induced by the microcracking front (namely, the red areas outlined by red and blue lines, based on the crack tip effect $[37,44])$, (iv) microcracking propagation, and (v) fully transformed monoclinic grain growth. (b) The distribution of the residual stresses on the whole membrane thickness of the 1100-HFM and 1250-HFM, respectively, before and after the $100 \mathrm{~h}$ hydrothermal ageing. 
Table 1 The cubic phase volume fraction (fc) of samples sintered at different temperatures were evaluated by XRD pattern using the Garvie and Nicholson's equation [22], and estimated by micro-Raman spectra using the ratios of the intensities of the Raman peaks $\sim 307 \mathrm{~cm}-1$ and $\sim 464 \mathrm{~cm}-1$ [29].

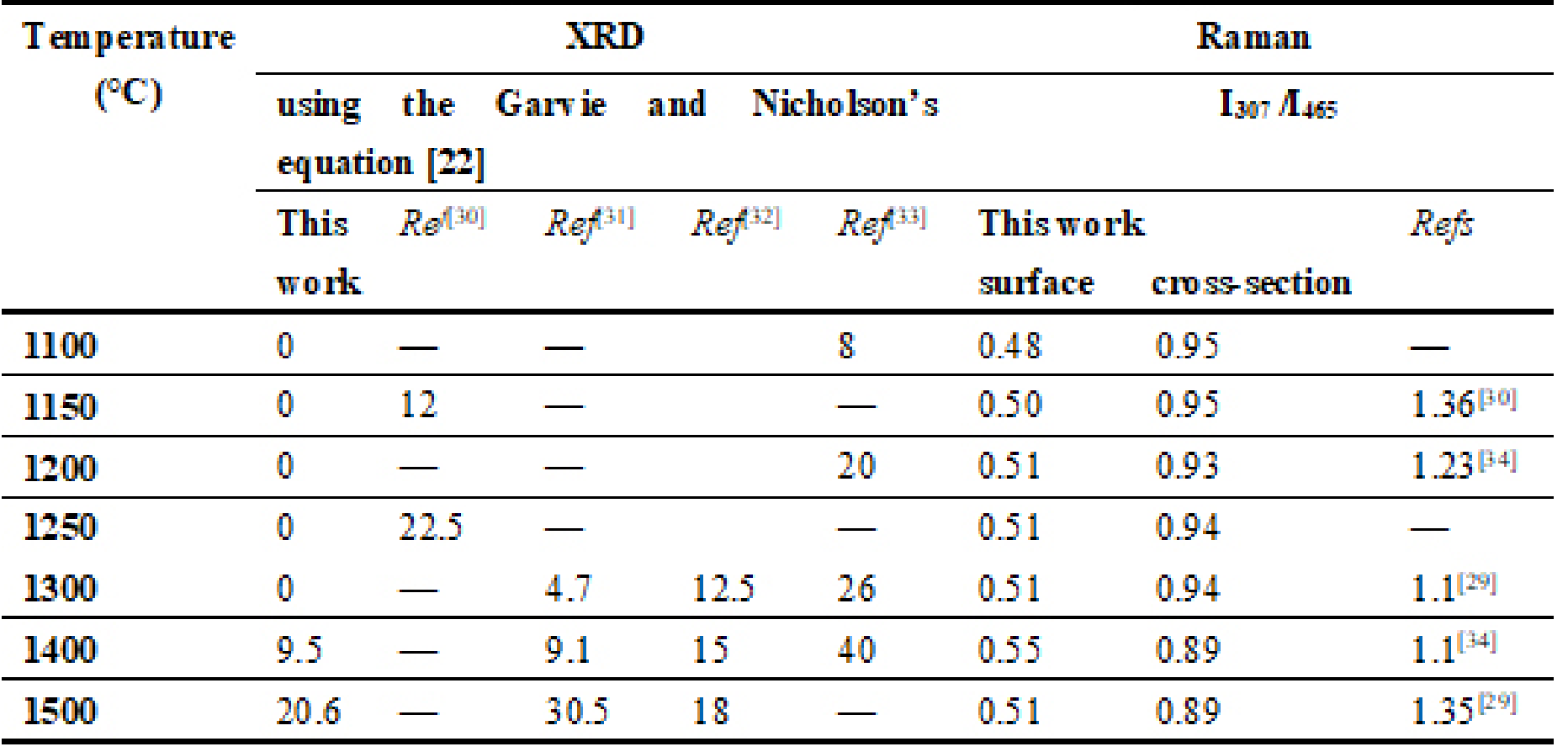

